\title{
Grain Boundary Serration in Nickel-Based Superalloy Inconel 600: Generation and Effects on Mechanical Behavior
}

\begin{abstract}
YUANBO T. TANG, ANGUS J. WILKINSON, and ROGER C. REED
Grain boundary serration in the superalloy Inconel 600 was studied. Two microstructural variants, one with nonserrated and the other with serrated grain boundaries were generated by altering the heat-treatment conditions, while keeping other aspects of the microstructure unchanged. The effect on the creep response between $700{ }^{\circ} \mathrm{C}$ and $900{ }^{\circ} \mathrm{C}$ was measured, and the different failure modes and accumulated damage were quantified using high-angular resolution electron backscatter diffraction analysis in the scanning electron microscope and also by X-ray computed tomography. It is found that serration plays a more crucial role in the high-temperature/low-stress regime when an intergranular cracking mechanism involving cavitation is operative; here it plays a role in improving both creep life and creep ductility. Any effect of serration is less prevalent at low temperatures where transgranular failure is dominant.
\end{abstract}

https://doi.org/10.1007/s11661-018-4671-7

(C) The Author(s) 2018

\section{INTRODUCTION}

SERRATION of grain boundaries in metals and alloys, for example the nickel-based superalloys of the type studied here, is intriguing for various reasons. First, there is complexity arising from the inapplicability of the generally accepted picture of smooth or gently curved grain boundaries, as observed on the microscale. Second, there is the fundamental question of why grain boundary serration arises in the first place. Third, effects of serration on the mechanical behavior of these materials are not well understood. What are the underlying fundamental effects which cause it? At present, no truly unequivocable explanation exists. Detailed experimentation involving carefully controlled measurements and high-resolution characterization is needed.

Serration of grain boundaries in nickel alloys was first reported by Larson et al. ${ }^{[1]}$ and Miyagawa et al. ${ }^{[2]}$ in 1976; slow cooling from above the $\gamma^{\prime}$ dissolution temperature was employed. Since then, attempts have been made to elucidate the formation mechanism, details of heat treatment and the role of alloy

YUANBO T. TANG and ANGUS J. WILKINSON are with the Department of Materials, University of Oxford, Parks Road, Oxford OX1 3PH, UK. Contact e-mail: yuanbo.tang@materials.ox.ac.uk ROGER C. REED is with the Department of Materials, University of Oxford and also with the Department of Engineering Science, University of Oxford, Parks Road, Oxford OX1 3PJ, UK.

Manuscript submitted January 23, 2018.

Article published online June 1, 2018 composition. $^{[3-11]}$ The study of Koul \& Gessinger on the Inconel 738, Nimonic 115 and Nimonic 105 alloys, ${ }^{[3]}$ involving an impressive combination of experimentation and modeling, identified the role of $\gamma^{\prime}$ migration on serration. The role of the $\gamma^{\prime}$ phase has since been confirmed by a number of researchers. ${ }^{[6,12-15]}$ But what happens in the absence of the $\gamma^{\prime}$ phase? Alloys containing very few or no $\gamma^{\prime}$-forming elements have also been shown to form serrated grain boundaries, for example Haynes 230, Inconel 690, Inconel 617, and Nimonic $263 .^{[7,10,16,17]}$ In this case, the formation mechanism for these alloys involves the triggering of serration by Cr-rich $\mathrm{M}_{23} \mathrm{C}_{6}$ carbide.

Is the phenomenon of grain boundary serration of mere academic interest, or are there significant beneficial effects which confer technological advantage? The time-dependent deformation has been shown to be improved dramatically by such features, particularly the creep ductility/lifetime and crack growth rate. Early research conducted on Inconel 792 and 20-11P confirmed reduced creep rate and increased creep strength, ${ }^{[1,2]}$ although the postmortem analysis was limited to the characterization techniques available at that time. Later studies on IN738, Astroloy, PM alloy-10, Waspaloy, and RR1000 have proven similar influences. ${ }^{[18-23]}$ The study up to date on STAL-15 again revealed similar trend - with both extensive experiments and modeling efforts. ${ }^{[24-26]}$ In addition, for alloys with low or no $\gamma^{\prime}$ phase, creep life and ductility are significantly enhanced. ${ }^{[7,27,28]}$ In summary, grain boundary serration has been demonstrated to improve mechanical properties such as creep, low cycle fatigue (LCF), and dwell fatigue remarkably in various superalloys. A few 
hypotheses have been proposed for taking into account of the improved behavior, e.g., prevention of grain boundary sliding, increased grain boundary diffusion path, and impedance of crack growth. However, no unambiguous mechanism is yet supported strongly by substantial experimental evidence or modeling. The past efforts have mostly been devoted to the serration effects from different angles in a qualitative manner, such as alloy composition, mechanical properties, and cooling rates, but little study has been attempted to control other microstructural variables at the same time. The most important missing part is that no quantitative measurements have been conducted in order to understand such phenomenon.

A further point relates to the complexity of the situation. Are the beneficial influences really contributed by grain boundary serration alone, or are there other changes to microstructural features due to slow cooling which are influential? In fact, few researchers have really addressed this issue, and studies on the serration effect have seldom reported very well-controlled microstructure, obviously due to the nature of the problem. Creep is one of the most complicated continuum damage processes, and many factors are well known to be crucial: grain size, $\gamma^{\prime}$ size, morphology and distribution, twin boundary fraction, carbide type/morphology, size, etc. All are likely to be affected by cooling rate to some extent. For example, the $\gamma^{\prime}$ size and distribution can be directly influenced by nucleation density within the $\gamma$ matrix, which is a function of solution-treatment condition and cooling rate. ${ }^{[4,8,23,29-31]}$ The slow cooling causes larger $\gamma^{\prime}$ size and sometimes a bimodal distribution. Moreover, slow cooling lengthens the total time required for grain growth and partial dissolution of $\mathrm{MC}$ carbides, ${ }^{[32,33]}$ which makes good control over microstructual variables even harder. Clearly, very carefully designed experimentation is needed.

The research reported in this paper was carried out keeping the above issues in mind. The nickel-based superalloy Inconel 600 is chosen for study; an advantage is then that the alloying elements $\mathrm{Al}$ and $\mathrm{Ti}$ are absent, so that any involvement of the $\gamma^{\prime}$ phase $\mathrm{Ni}_{3}(\mathrm{Al}, \mathrm{Ti})$ on the serration effect cannot then arise. Furthermore, any role by Ta- or W-rich MC carbides is avoided, because $\mathrm{Ta}$ and $\mathrm{W}$ are absent. Instead, as will be shown, $\mathrm{Cr}$-rich carbide species become critical to the development of grain boundary serration, with the cooling rate through the carbide solvus temperature also playing a crucial role. Here, serrated and nonserrated grain boundaries were first prepared and characterized using scanning electron microscopy, with the grain size distribution and twin boundary fractions having proven to be unchanged; the creep response was then tested. Quantitative high-angular resolution electron backscatter diffraction (HR-EBSD) and X-ray computed tomography (XCT) are used to gain insights into the creep deformation modes which are operative. Attention is paid not only to postmortem analysis, but also to interrupted studies. In the final part of the paper, the implications of the serration effect on the mechanical response of this alloy are considered with an emphasis on carbide evolution, cavitation, and dislocation substructures which arise.

\section{METHODOLOGY AND EXPERIMENTAL DESCRIPTION}

Inconel 600 was chosen for the current study, on account of the relative simplicity of its chemical composition, Table I. In this alloy, Al or Ti is present at only trace levels so that any influence of the $\gamma^{\prime}$ phase on grain boundary serration cannot then arise. Moreover, refractory elements such as Ta, Mo, and W are also absent; therefore, grain boundary MC-type carbides enriched with these elements have no contribution to microstructure; neither $\mathrm{M}_{23} \mathrm{C}_{6}$ nor $\mathrm{M}_{7} \mathrm{C}_{3}$ carbides could be formed from MC-carbide decomposition. Specimens were taken from a cold-drawn and annealed bar of circular cross section with a diameter of $16 \mathrm{~mm}$, in which the virgin grain size was about $15 \mu \mathrm{m}$.

\section{A. Heat Treatment}

Heat treatment was carried out in two ways in order to develop different grain boundary morphologies, i.e., serrated and nonserrated (straight or gently curved). A solution heat-treatment temperature of $1140{ }^{\circ} \mathrm{C}$ for 2 hours was used throughout, which is significantly higher than the estimated carbide solvus temperature of $1020{ }^{\circ} \mathrm{C}$ calculated using the ThermoCalc software. Such solution heat treatment was employed to maintain the same level of grain size, grain distribution, and $\Sigma 3$ twin boundary fraction in both microstructures, which are considered to be crucial microstructural variables for creep and other mechanical properties. The selected heat treatment compensated for small variations in total heat-treatment time caused by different cooling rates, and it proved the possibility to develop significant grain boundary serration at the microstructural level. This was achieved by cooling the material beyond the carbide solvus temperature at $12{ }^{\circ} \mathrm{C} / \mathrm{min}$, measured by $\mathrm{N}$-type thermocouples, in contrast to water quenching for nonserrated grain boundaries. Heat-treatment profiles and representative microstructures are illustrated in Figure 1.

\section{B. Creep Testing}

The impact of grain boundary serration on mechanical behavior was assessed from $700{ }^{\circ} \mathrm{C}$ to $900{ }^{\circ} \mathrm{C}$ by tensile creep rupture tests. Creep test specimens were

Table I. Nominal Composition of the Alloy Studied in Weight Percent (Ni-Base)

\begin{tabular}{lccccccccr}
\hline Name & $\mathrm{Ni}$ & $\mathrm{Cr}$ & $\mathrm{Fe}$ & $\mathrm{C}$ & $\mathrm{Mn}$ & $\mathrm{Si}$ & $\mathrm{Co}$ & $\mathrm{Cu}$ & $\mathrm{S}$ \\
\hline Inconel 600 & 74.1 & 15.9 & 9.03 & 0.068 & 0.21 & 0.27 & 0.012 & 0.0018 & 0.001 \\
\hline
\end{tabular}




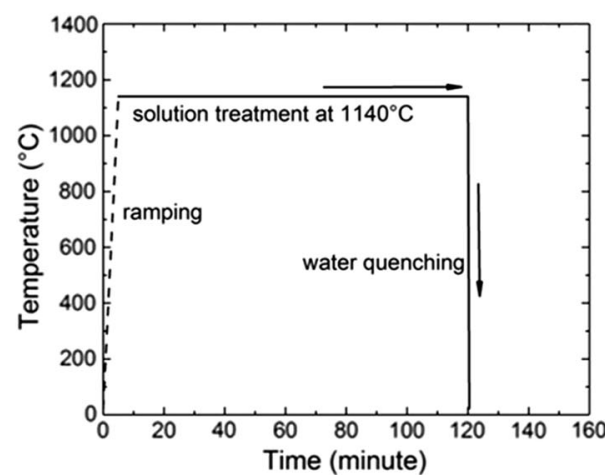

(a)

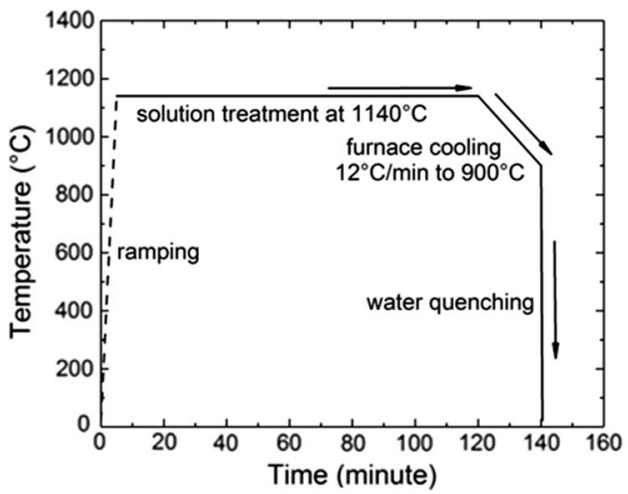

(b)

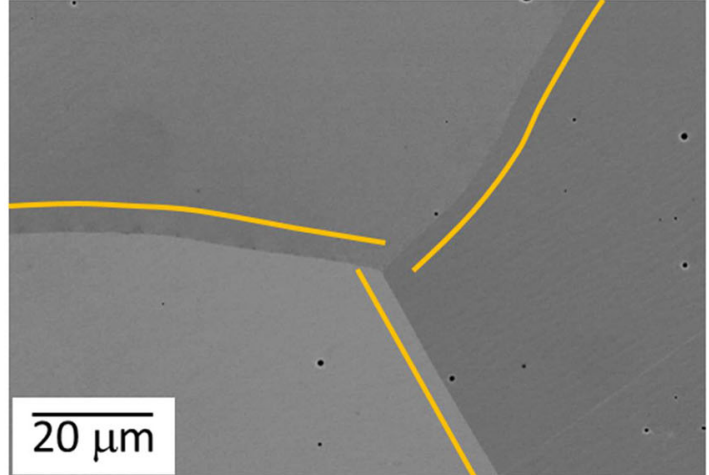

(c)

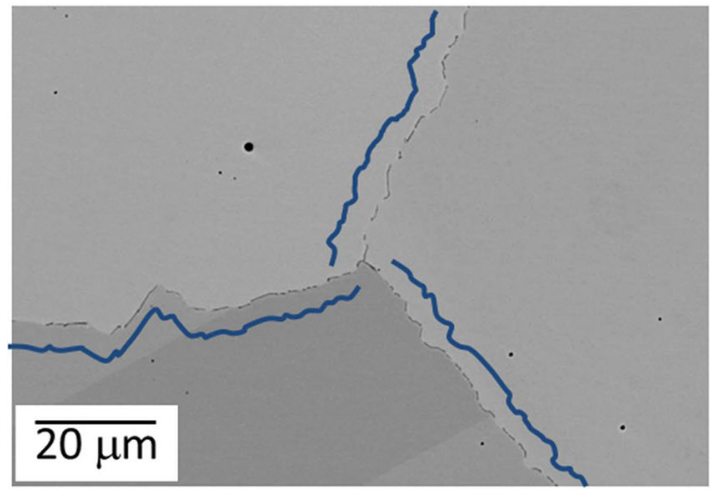

(d)

Fig. 1- $(a)$ and $(b)$ : Heat-treatment profiles for development of nonserrated and serrated grain boundary materials and $(c)$ and $(d)$ corresponding microstructures obtained from heat treatments described in (a) and (b). The curves are drawn to illustrate grain boundary morphologies only and are deliberately offset in order not to obscure the grain boundaries in the micrographs.

machined from heat-treated cylindrical bars, diameters of which were reduced from 16.4 to $4 \mathrm{~mm}$ after heat treatment to avoid any effect of oxidation damage on specimen gauge section. Creep tests were carried out under three conditions for both microsturctures, using specimens of $4 \mathrm{~mm}$ diameter and $20 \mathrm{~mm}$ length (3 tests under each condition). An Instron 8862 servoelectric machine was used, where the strain was measured using an electromechanical actuator equipped in the lower end of the crosshead operated at a frequency of $1 \mathrm{~Hz}$ with the precision of $1 \mu \mathrm{m} / \mathrm{h}$. In addition, another six tests were interrupted at 5 pct strain, to observe deformation and fracture mechanisms under each condition to evaluate the influence of serration. The tests were carried out under different conditions of significant variations in temperature and stress: $700{ }^{\circ} \mathrm{C} / 170 \mathrm{MPa}$, $815^{\circ} \mathrm{C} / 70 \mathrm{MPa}$, and $900{ }^{\circ} \mathrm{C} / 40 \mathrm{MPa}$. Temperature was monitored using K-type thermocouples placed in contact with the specimen. Each specimen was held at the testing temperature for 1 hour prior to loading.

\section{SEM-Based Characterization}

The grain structure and boundary types produced by the two heat treatments were characterized using a Zeiss Merlin high-resolution field emission gun scanning electron microscope (FEG-SEM) that was also used for the fractography and HR-EBSD scans. For each condition, a representative sample, i.e., the sample with median rupture life among three, was first taken for fractography analysis. The fractured sample was then cut by wire-based electrical discharge machining (EDM) from the middle of fracture tip along the axial direction. The sectioned sample was mounted and then prepared via standard metallography procedures, with 2 minutes colloidal silica for finishing. The SEM is equipped with a Bruker EBSD detector, which was used to capture EBSD patterns at a resolution of $600 \times 800$ for maps collected at a step size of $220 \mathrm{~nm}$. Furthermore, six interrupted specimens were also cut by EDM in the same way and scanned by HR-EBSD using the same conditions. A cross-correlation-based analysis was used on the stored EBSD patterns. ${ }^{[34-36]}$

\section{X-ray Tomography-Based Characterization}

Since the reduction in area and cracking from grain boundaries in the crept samples were found to be significant, X-ray computed tomography was used to quantify cavity size and its distribution. One representative fracture tip was taken for each creep condition and tomography analysis carried out using a North Star Imagix system at $150 \mathrm{kV}$ and a current of $27 \mu \mathrm{A}$, which defined a voxel size of $4.86 \mu \mathrm{m}$. For each sample, a height of roughly $10 \mathrm{~mm}$ was characterized using 3600 projections and a helical scan used to reconstruct the $3 \mathrm{D}$ 


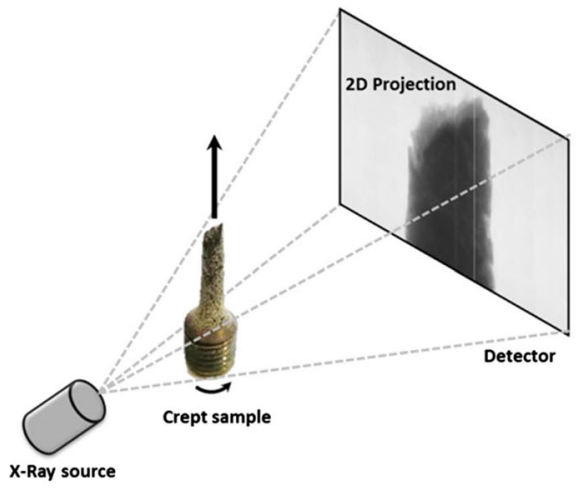

(a)

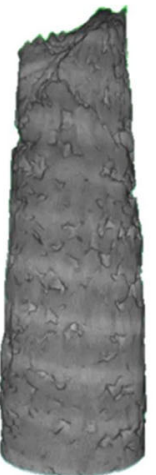

(b)

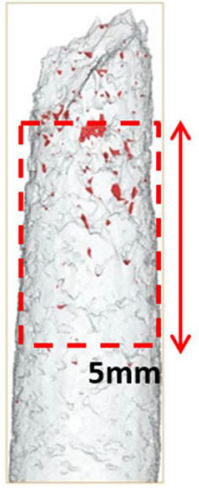

(c)

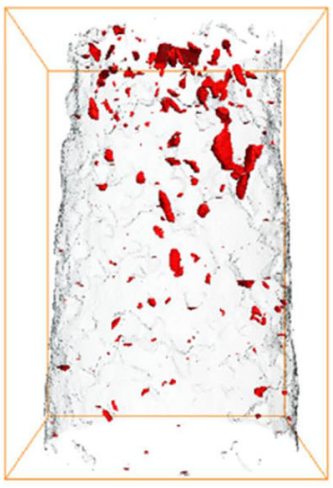

(d)

Fig. 2-Postmortem X-ray tomography setup and computed results-quantification of cavitation distribution. (a): X-ray technique setup. (b): Volume of the specimen reconstructed by X-ray tomography. (c) Surface reconstruction completed by Avizo with internal cavities labeled in red. (d) A cylindrical volume of $5 \mathrm{~mm}$ height from lower end of the fracture tip was used for cavity size and distribution analysis (Color figure online).
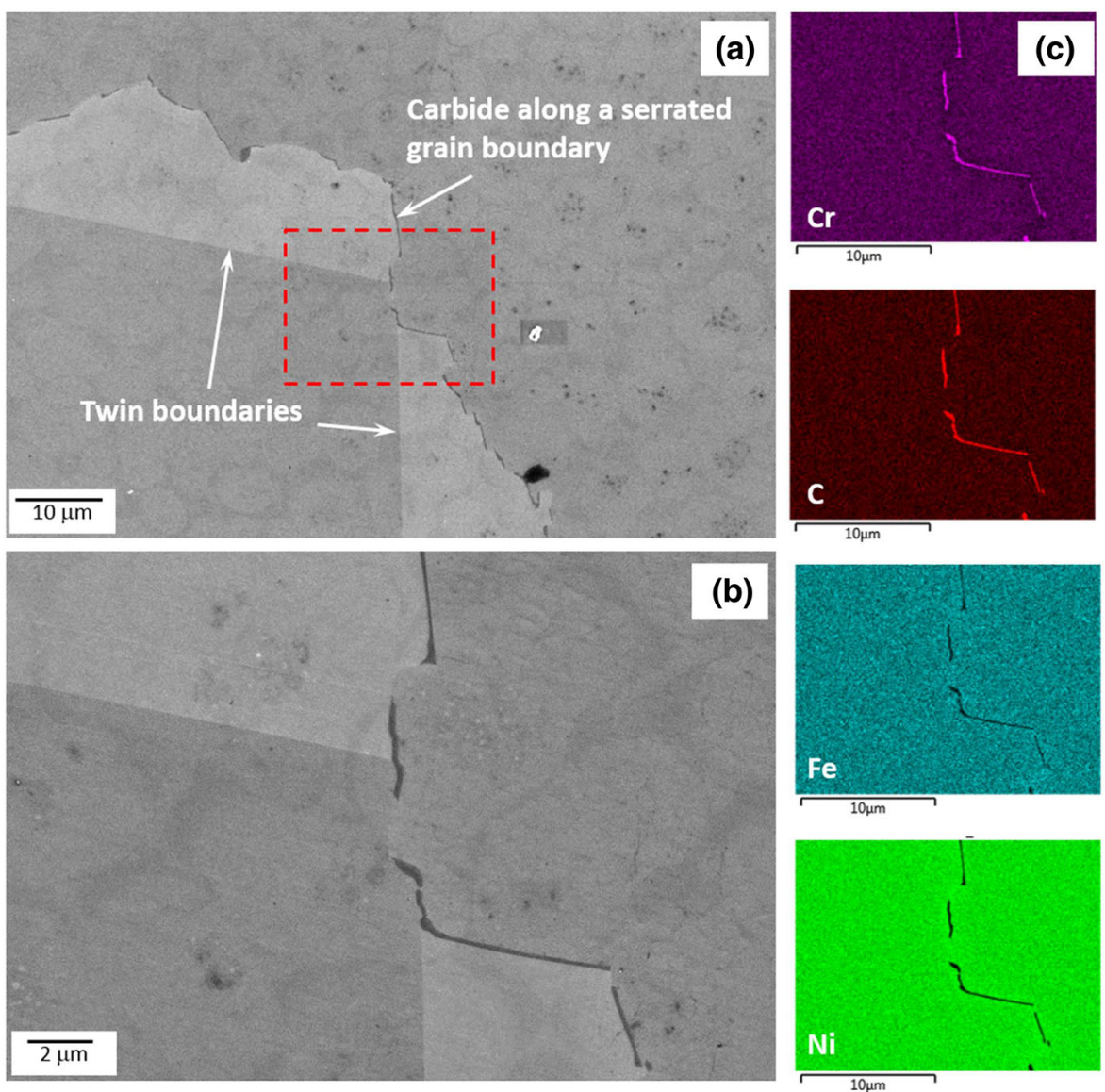

Fig. 3-Energy dispersive X-ray spectroscopy (EDS) analysis in a region that contains a serrated grain boundary and planer carbides. (a) and (b) show the regions at two magnifications. $(c)$ : Composition maps indicate segregation of $\mathrm{Cr}$ and $\mathrm{C}$ and depletion of $\mathrm{Fe}$ and $\mathrm{Ni}$ at the grain boundary. The dark phases are determined as Cr-rich Carbide.

volume. ImageJ and Avizo softwares were utilized for quantification of cavity size and distribution using histogram-based methods. ${ }^{[37]}$ Comparisons of cavity size and distributions were then made for samples with and without grain boundary serration. For this, quantification of a 3D cylindrical volume of about $3 \mathrm{~mm}$ diameter and $5 \mathrm{~mm}$ height was selected as illustrated in Figure 2. 


\section{RESULTS}

\section{A. Heat Treatment and Grain Boundary Serration Development}

The profiles of heat treatment that generated each type of grain boundary morphology are shown in Figures 1(a) and (b). Backscatter electron imaging in the FEG-SEM revealed grains and carbides due to the channeling effect and compositional contrast. Typical microstructures produced from each cooling rate are shown in Figures 1(c) and (d); for illustration purposes, curves highlighting the grain boundary morphologies are displaced laterally from the actual boundaries. For the nonserrated grain boundary case, no secondary phases were observed at the FEG-SEM resolution; however, the serrated grain boundaries were always associated with intergranular carbides at the microscale. High-resolution energy dispersive X-ray spectroscopy (EDS) was used to probe the chemical compositions of such carbides on a serrated grain boundary, and Figure 3 shows a typical composition map. This and other similar maps determined the carbides to be enriched in chromium but depleted in iron and nickel.
Grain size and twin boundary fractions can have great influences on creep, and so they were measured for both microstructures using EBSD over large sampling areas for achieving statistically meaningful estimates. Three random regions of each sample were mapped with EBSD to cover over 800 grains for each microstructure. The EBSD data were then postprocessed using the ESPRIT software, with a threshold grain boundary misorientation angle defined as $10 \mathrm{deg}$. Representative EBSD maps are illustrated in Figures 4(a) and (b) for the nonserrated and serrated microstructures, respectively. Grain size distribution histograms are shown in Figures 4(c) and (d), where two distributions overlap with each other and both are skew with tails on the high grain size side. Mean values of grain size with boundary length fraction of $\Sigma 3$ (twin) boundaries are given on the distribution plots and show very little variation between the two microstructures.

Postprocessed EBSD results on misorientation angles demonstrated that negligible low-angle $(<15 \mathrm{deg})$ grain boundaries were present after heat treatment, which suggests dislocation arrays/polygonization were minimized. While the mechanism in relation to serration

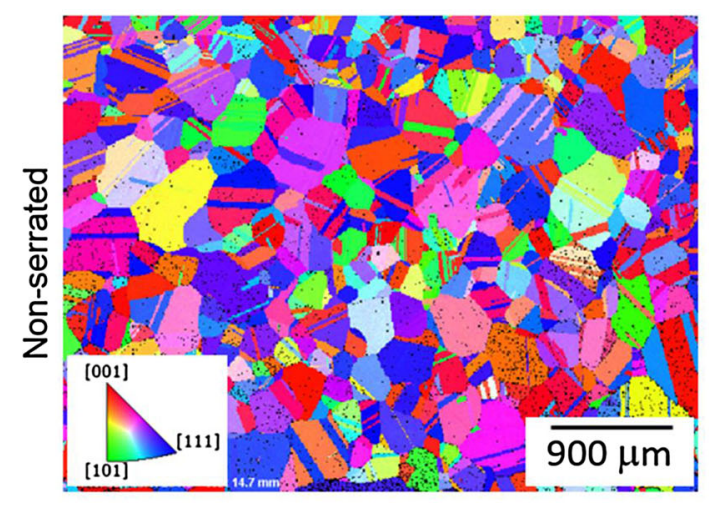

(a)

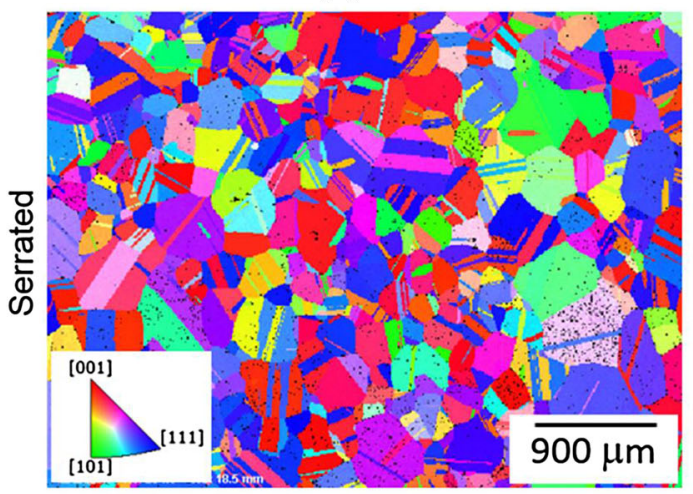

(b)

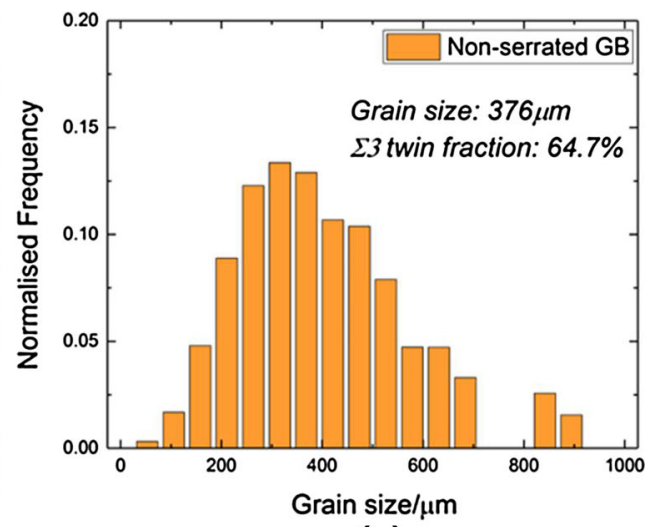

(c)

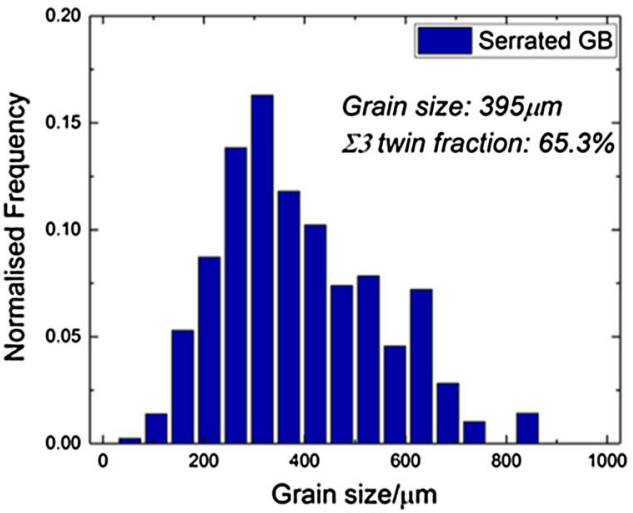

(d)

Fig. $4-(a)$ and (b) Examples of inverse pole figure maps used for grain size measurements for nonserrated and serrated materials, respectively. $(c)$ and $(d)$ Grain size distributions for each microstructure. Average grain sizes are 376 and $395 \mu \mathrm{m}$; twin boundary area fractions are 64.7 and $65.3 \mathrm{pct}$, respectively, for nonserrated and serrated grain boundary materials (Color figure online). 


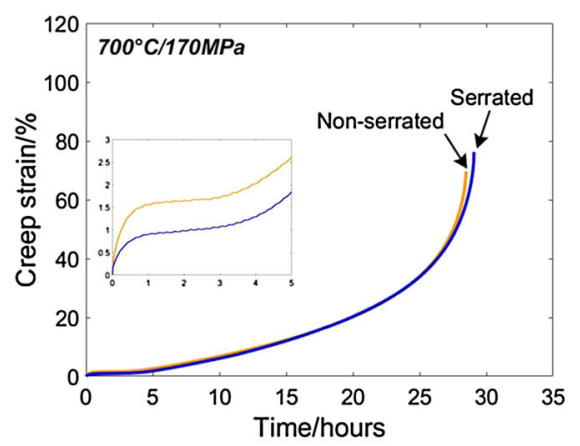

(a)

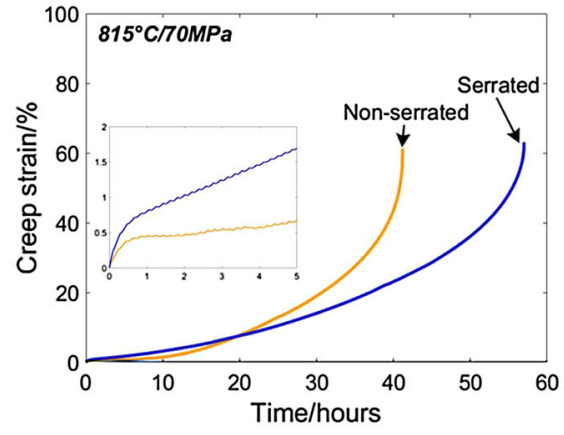

(b)

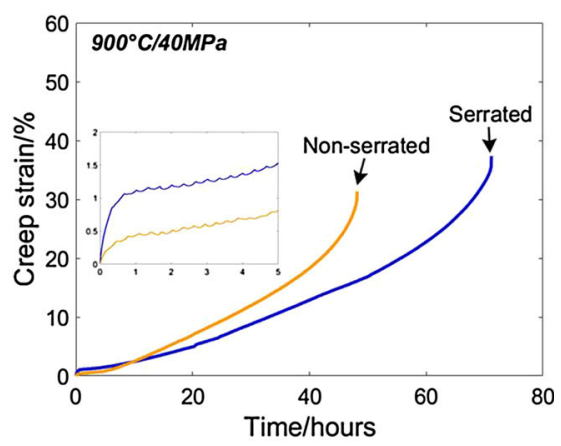

(c)

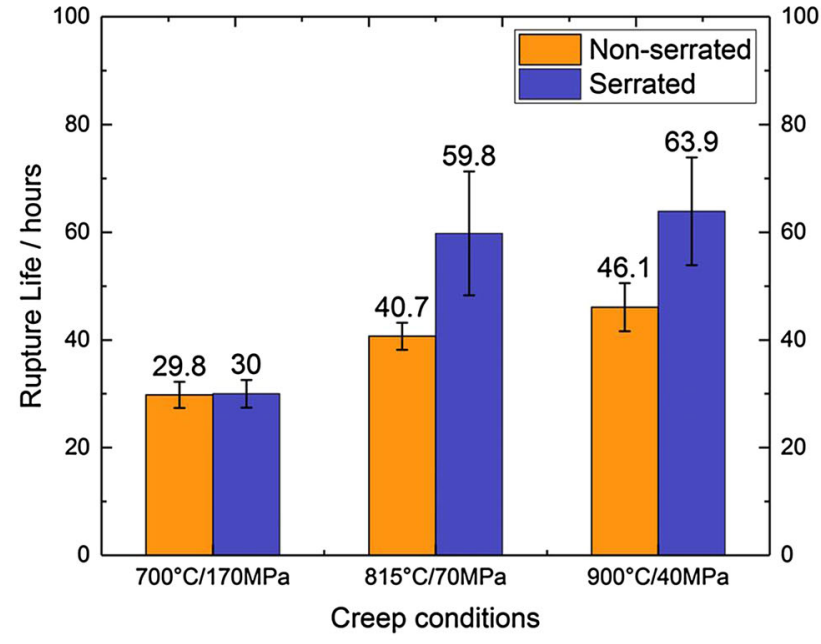

(d)

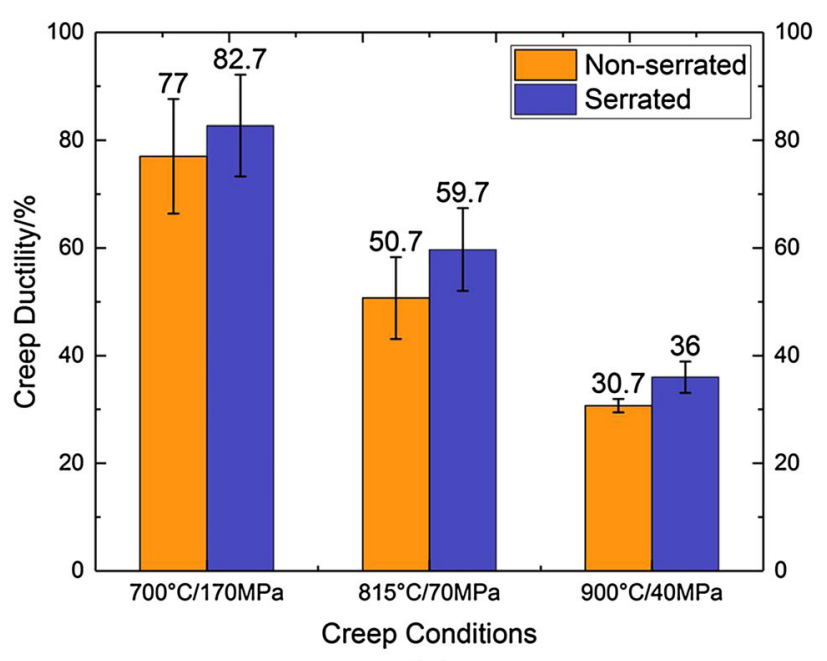

(e)

Fig. 5- Creep data for nonserrated and serrated architectures, ( $a$ through $c$ ) under conditions of $700{ }^{\circ} \mathrm{C} / 170 \mathrm{MPa}, 815^{\circ} \mathrm{C} / 70 \mathrm{MPa}$, and $900{ }^{\circ} \mathrm{C} /$ $40 \mathrm{MPa}$. Top row: Representative creep curves for median rupture life samples. $(d)$ demonstrated average rupture lives displayed with error bars. (e) Demonstrated average ductility displayed with error bars. Serrated grain boundary shows no creep life improvement at $700{ }^{\circ} \mathrm{C}$, but, enhancements at $815^{\circ} \mathrm{C}$ and $900{ }^{\circ} \mathrm{C}$. Creep ductility was increased by a moderate margin under all conditions (Color figure online).

formation is out of this paper's scope, some measurements have, however, been performed on serration generation. The serration amplitude is found to be a function of cooling rate. For the given solution treatment used here, the serration amplitude varied between 300 and $600 \mathrm{~nm}$. In addition, although grain sizes were shown unchanged under both cooling rates, grain boundary lengths were increased due to the presence of local serrations. In total, six random serrated grain boundaries were analyzed using ImageJ software to compare measurements along the serrated path, the actual length to end-to-end straight-line distance. The result shows serrations increase by $54 \pm 11$ pct of the grain boundary length compared to perfectly straight boundaries. The same procedure was completed for nonserrated case to account for curvature of boundaries. The nonserrated boundaries are also longer than straight-line paths range curvature which increased the length by $29 \pm 8$ pct of the grain boundary length.

\section{B. Creep Tests and Fractography}

Creep curves measured at $700{ }^{\circ} \mathrm{C} / 170 \mathrm{MPa}, 815^{\circ} \mathrm{C} /$ $70 \mathrm{MPa}$, and $900{ }^{\circ} \mathrm{C} / 40 \mathrm{MPa}$ for both nonserrated and serrated grain boundaries samples are presented in
Figure 5. The top row presents the creep curves of samples with median rupture life in each condition. The bottom row displays a summary of rupture life and creep ductility with error bars representing \pm one standard deviation. For rupture life, the serrated grain boundary microstructure conferred no life enhancement at $700{ }^{\circ} \mathrm{C}$. However, an increase in creep rupture life was measured at the higher test temperatures of $815^{\circ} \mathrm{C}$ and $900{ }^{\circ} \mathrm{C}$. From the average creep ductility, it is evident that serrated grain boundary surpassed the nonserrated under all conditions by a moderate margin. In addition, for both microstructures, a drop in ductility was evident at higher-temperature and lower-stress levels, which suggests a change in fracture mechanism.

Fracture surfaces of samples under each condition were characterized by FEG-SEM, for which illustrative results are given in Figure 6. Specimens with both microstructures showed similar transition behavior from low to high temperature in deformation. A clear shift from transgranular-dominant features at low temperature to intergranular-dominant cracking at higher temperatures was observed. The largest difference was seen under the $815^{\circ} \mathrm{C} / 70 \mathrm{MPa}$ condition, for which the serrated samples remained mostly transgranular, whereas the nonserrated sample showed much more 

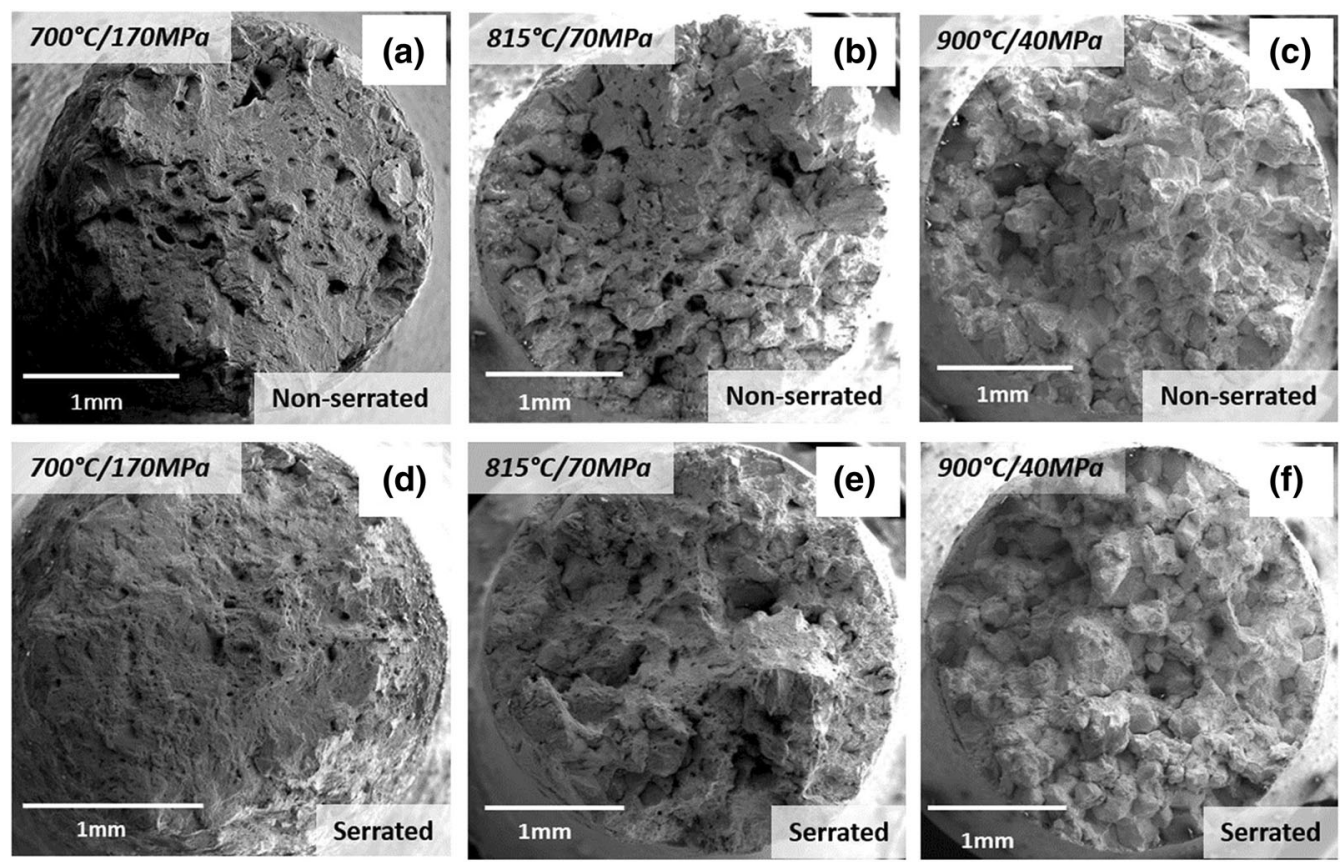

Fig. 6-Fractography on representative samples under various conditions with nonserrated grain boundary, ( $a$ through $c$ ) and with serrated grain boundary, $(d$ through $f)$. (a): Transgranular-dominant deformation with limited signs of intergranular cracking, i.e., a few microvoids. (b) Intergranular-dominant cracking with limited transgranular deformation. (c): Intergranular cracking. (d): Transgranular-dominant deformation (e): Mixed-mode of trans/intergranular cracking. (f): Intergranular cracking.

evidence of intergranular processes. This is believed to account for the marginal increase of ductility observed.

Cross sections of fracture tips under each condition were scanned using EBSD at a low magnification. Figures 7 and 8 demonstrate crystal orientation and grain boundary type at fracture for nonserrated and serrated samples, respectively. Pattern quality maps were overlain with grain boundary, twin boundary, and subgrain boundary $(<5 \mathrm{deg})$ next to EBSD maps. It is clear to see the contrast of cavitation behaviors between the two microstructures, particularly under $700{ }^{\circ} \mathrm{C}$ and $815^{\circ} \mathrm{C}$ conditions, where notably more cavities were formed in the nonserrated case. In addition, twin boundaries in each case displayed higher integrity, and no cracks were found to propagate through them despite the absence of carbides.

\section{HR-EBSD on Fractured Specimens}

Cross-correlation HR-EBSD analyses was performed on sections through fractured samples that had been tested under the $815^{\circ} \mathrm{C} / 70 \mathrm{MPa}$ and $900{ }^{\circ} \mathrm{C} / 40 \mathrm{MPa}$ conditions. Geometrically necessary dislocation (GND) density maps were calculated using the method described in References 35 and 38. Dislocation cell structures consisting of high GND density walls and low GND density interiors were developed within the grains after the large strain (over 0.3) creep deformation, Figure 9. Cell sizes were measured for each specimen by drawing 10 straight lines across each map (horizontally and vertically) and then counting the number of intersections with cell walls. Cell walls were defined by a minimum threshold GND density of $2 \times 10^{14} \mathrm{~m}^{-2}$, suggested by previous study on face-centered cubic (FCC) copper ${ }^{[39]}$ For both microstructures, the cell size increased with the decreasing stress, from 4.4 to $5.2 \mu \mathrm{m}$ for the nonserrated case and from 4.8 to $6.8 \mu \mathrm{m}$ for the serrated case. Under the same test conditions, the nonserrated microstructure always exhibited a smaller cell size than that for the serrated case.

\section{Interrupted Creep Test}

The evolution of the carbide distribution during the interrupted creep tests was explored using backscattered electron (BSE) imaging of sectioned samples. Figure 10 shows images of the nonserrated and serrated microstructures after creep to 5 pct strain at $900{ }^{\circ} \mathrm{C}$. Image intensity was used to segment the images and identify the carbides which are shown alongside the BSE images in Figure 10. For the nonserrated microstructure a relatively uniform dispersion of fine carbides develop across the grain interiors. In contrast, the carbide dispersion that develops in the serrated microstructure is heterogeneous and shows much greater number density nearer to the grain boundaries than toward the center of the grains. The average carbide size is larger in the serrated case $(1000 \mathrm{~nm})$ compared with the nonserrated case $(520 \mathrm{~nm})$. The other striking feature is that for the serrated case, the carbides are clearly dispersed along bands in well-defined directions within each grain. Figure 11 compares carbide distributions in the serrated microstructure after testing at $900{ }^{\circ} \mathrm{C}$ and $815^{\circ} \mathrm{C}$ and shows that the bands of carbides occur for both test conditions and are aligned with traces of expected $\left\{\begin{array}{lll}1 & 1 & 1\end{array}\right\}$ slip systems as determined by EBSD. 

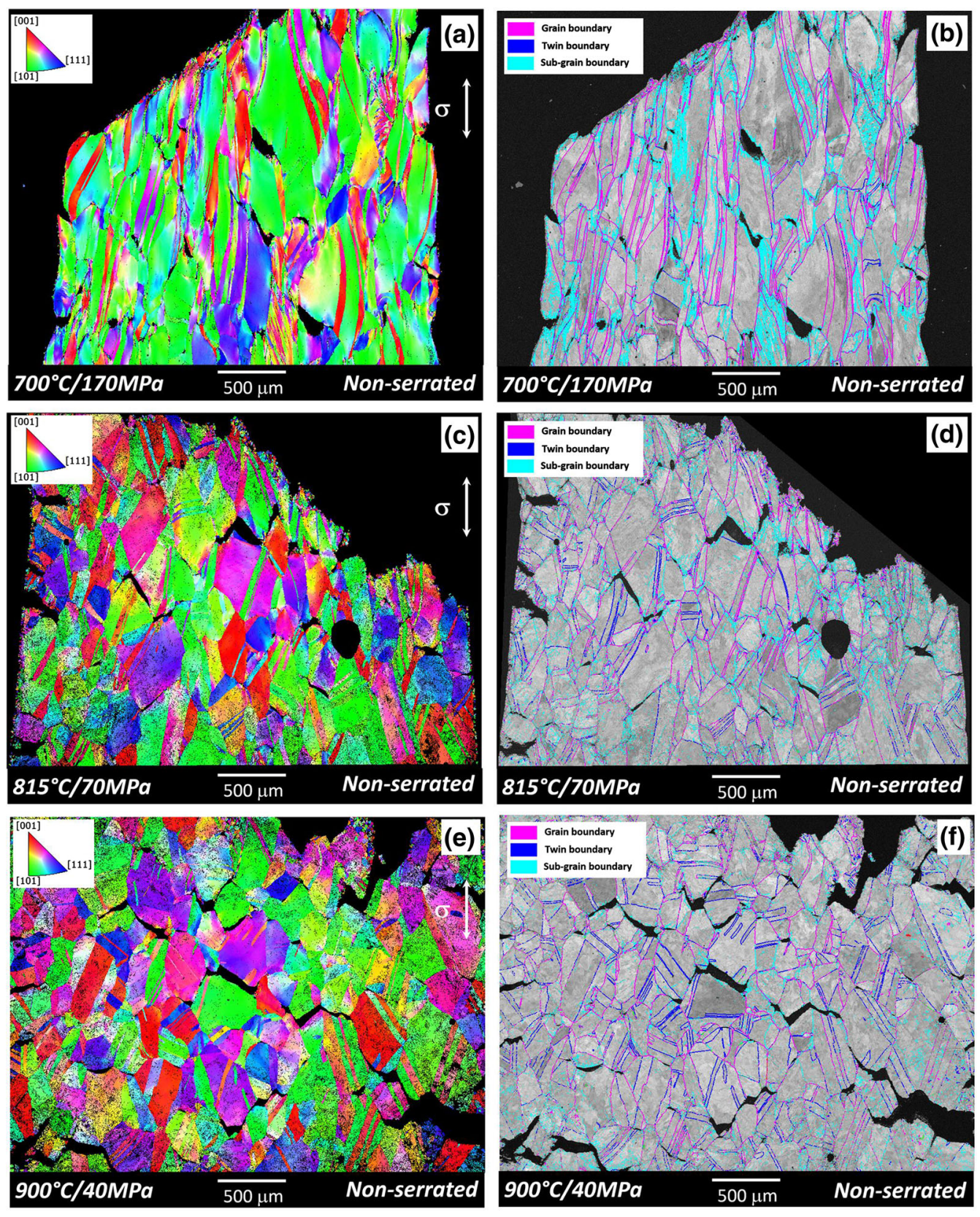

Fig. 7-Inverse pole figures (IPF) corresponding to X-axis $(a),(c)$, and $(e)$ and pattern quality maps $(b),(d)$, and $(f)$ of nonserrated fracture tips under each creep condition. The pattern quality maps are overlain with grain boundary, twin boundary, and subgrain boundary. Cavitations exhibited were mostly of intergranular cracking in all samples. The same circular black spot is displayed both in (c) and (d), caused by surface contamination rather than cavitation (Color figure online).

HR-EBSD was also conducted on sectioned samples from the interrupted tests. At the lowest test temperature of $700{ }^{\circ} \mathrm{C}$, there were quite obvious differences between GND density distributions for the two microstructures, as shown in Figure 12. For the nonserrated case, there are some linear bands of increased GND density that are aligned with the $\left\{\begin{array}{lll}1 & 1 & 1\end{array}\right\}$ slip plane traces in each grain, but there is little evidence of higher GND density near the grain boundaries suggesting slip transfer was relatively easy. In contrast, for the serrated case, there is very marked and obvious accumulation of increased GND density near the grain boundaries.
Alignment of increased GND density regions into straight linear features is less marked, and there is evidence of dislocation cell formation near the grain boundaries. This suggests a more difficult slip-transfer process for the serrated grain boundaries.

At $815^{\circ} \mathrm{C}$, Figure 13, the straight linear features are suppressed for both microstructures. For the nonserrated case, there is increased GND density and dislocation cell formation near the triple junctions, and to a lesser extent, where twin boundaries intersect with high-angle grain boundaries. For the serrated case, the GND density is markedly higher in regions close to 

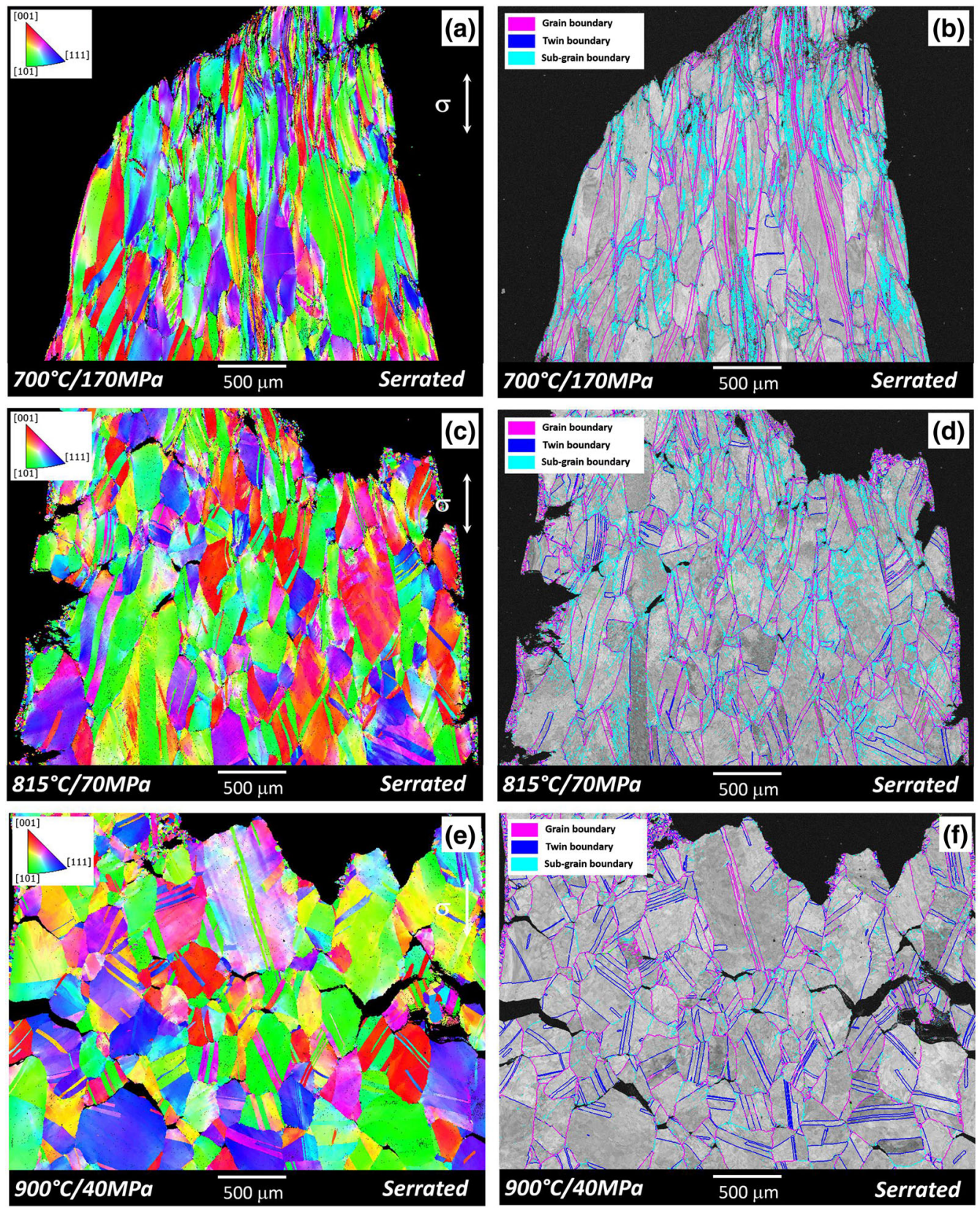

Fig. 8-Inverse pole figures (IPF) corresponding to X-axis $(a),(c)$, and $(e)$ and pattern quality maps $(b),(d)$, and $(f)$ of serrated fracture tips under each condition. The pattern quality maps are overlain with grain boundary, twin boundary, and subgrain boundary. Little cavitations were exhibited in $700{ }^{\circ} \mathrm{C}$ sample, and cavitations mostly of intergranular cracking were exhibited in other samples (Color figure online).

high-angle grain boundaries (not twins), with the highest densities associated with triple junctions.

At the highest test temperature used, Figure 14, the GND density after 5 pct strain is reduced compared to lower temperature tests, and the accumulation of GND density near grain boundaries is less marked. There is little evidence of GND density accumulation near the triple junction toward the center of the map for the nonserrated case, although the density is increased near the intersection of a twin boundary with a general high-angle grain boundary. Accumulation of increased
GND density around the intragranular carbides is evident, and it is most obvious for the serrated case where the carbides are larger and aligned along slip bands.

\section{E. X-ray Tomography Technique}

For understanding the creep behavior in greater detail, the X-ray tomography technique was employed to characterize cavitation damage in each condition and microstructure. 3D reconstructed surfaces of each 

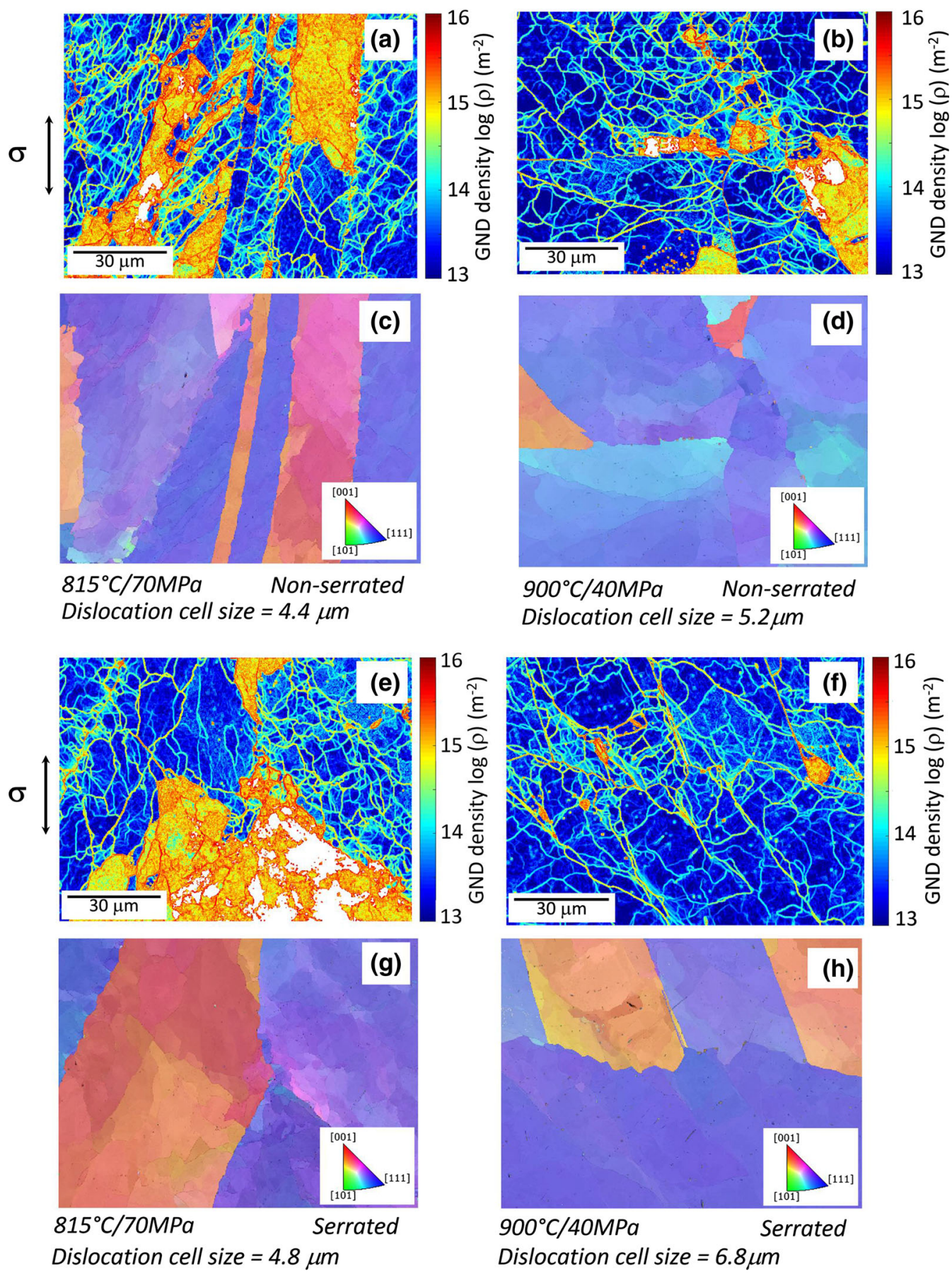

Fig. 9- $(a),(b),(e)$ and $(f)$ displayed GND density maps obtained from $815^{\circ} \mathrm{C} / 70 \mathrm{MPa}$ and $900{ }^{\circ} \mathrm{C} / 40 \mathrm{MPa}$ for both materials, along with the inverse pole figure map corresponding to Y-axis, see $(c),(d),(g)$ and $(h)$. Dislocation substructures are clearly revealed in each map. Cell sizes increase with stress level. In particular, nonserrated specimens display smaller cell size than serrated ones in both conditions (Color figure online).

fracture tip showing cavitation (labeled red) distributions across the specimen are displayed in Figures 15(a) through (c) for nonserrated, and (d) through (f) for serrated microstructures. Figure 16 shows the number density of cavitation vs distance from fracture tip. In general, cavities are at higher density and coarser near the fracture tip, and the damage declines slightly over distance from its fracture surface. To describe the damage caused by cavitation quantitatively, two metrics are considered here: cavitation frequency and total volume of cavitation. Cavitation frequency-contributed predominantly by small cavities - increased dramatically from $700{ }^{\circ} \mathrm{C}$ to $900{ }^{\circ} \mathrm{C}$, i.e., from 714 to 3813 counts for the nonserrated and from 46 to 6194 counts for the serrated. On the other hand, cavitation volume are contributed mostly by larger cavities. It 

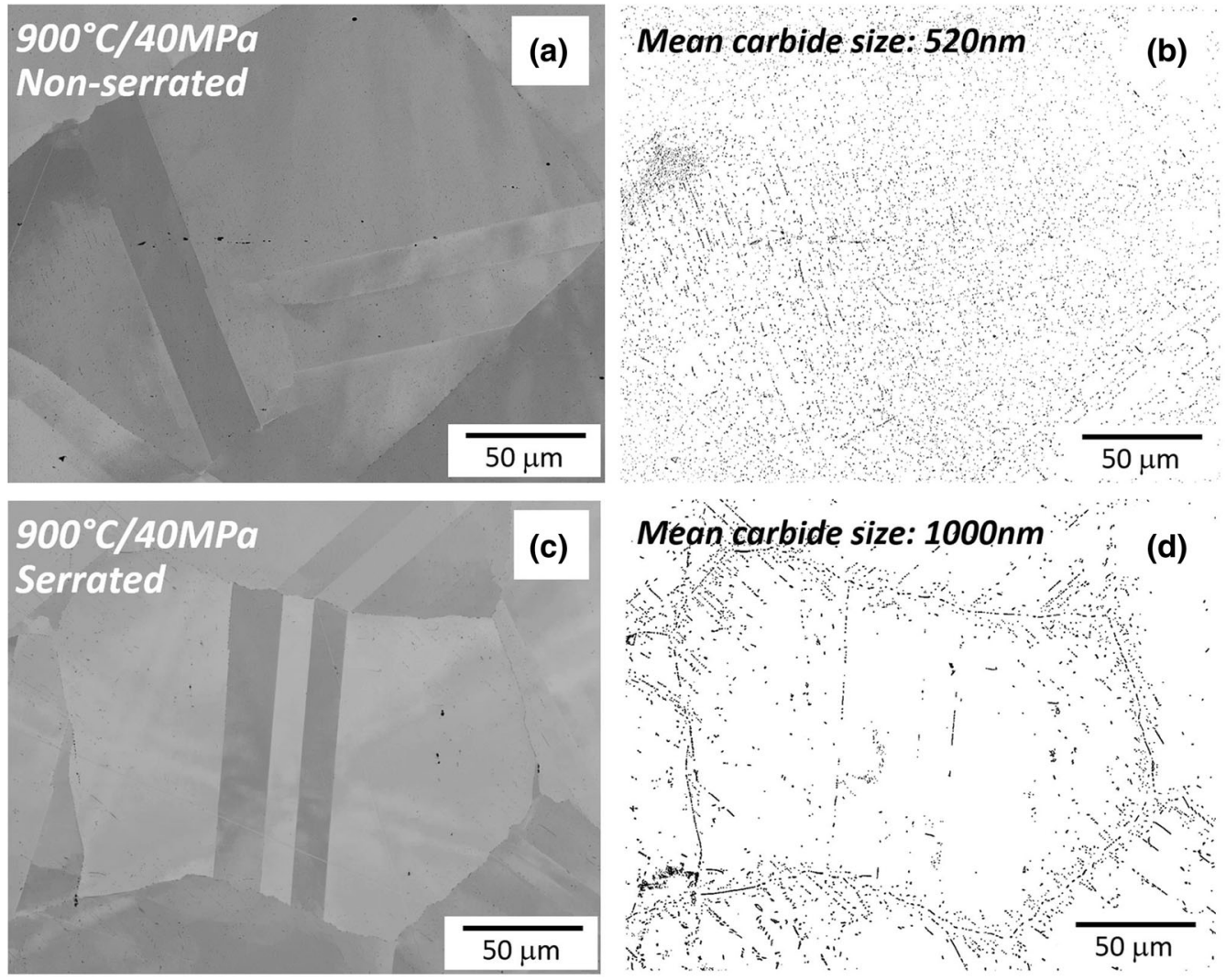

Fig. 10 - Carbide distribution within grain interior and in vicinity of grain boundaries. ImageJ has been utilized for outlining carbides. ( $a$ ) and $(c)$ are the backscattered image of the nonserrated and serrated material from creep tests interrupted at 5 pct strain. $(b)$ and $(d)$ are the graphs with outlined carbides. Carbides are fine and evenly distributed in nonserrated grain boundary material. By contrast, carbides are coarser and elongated in serrated material, predominantly distributed near grain boundary region with specific orientations.

implies the degree of porosity in the material and effectiveness of small-crack coalescence, which reduced gauge area and accelerated the fracture. Thus, this is considered to be the better metric of cavitation damage.

\section{DISCUSSION}

The heat treatments applied to Inconel 600 in the study have successfully generated two distinctive grain boundary morphologies, i.e., serrated and nonserrated, while maintaining the other microstructural aspects same, thus allowing the isolation of the effects of serration on creep deformation. In summary, the results clearly demonstrate three key findings. First, for both microstructures, a transition from transgranular-tointergranular fracture was observed with the increasing temperature and the decreasing stress. This transition was offset to higher temperatures by grain boundary serration. Second, grain boundary serration has demonstrated great impact on creep properties in Inconel 600; in particular, it promotes enhancement in creep rupture life at high temperatures. However, at the lowest test temperature, no measurable difference was found. Third, the carbide distribution evolves significantly during creep testing and is distinctively different in the two microstructures. These different carbide distributions affect the movement and accumulation of dislocations during creep.

\section{A. Carbide Distribution and Its Evolution}

For the interrupted condition, the carbide distributions were distinct for the two microstructures - homogeneous fine carbides in the nonserrated case and heterogeneous, coarse carbides in the serrated case. This is a phenomenon caused by a combination of the heat treatment and subsequent creep deformation. In the conventional quenched nonserrated case, carbon atoms are relatively uniformly dispersed, so a uniform dispersion of carbides during thermal exposure in testing was obtained. The nonconventional slow cooling leads to strong segregation of carbon atoms to grain boundaries and triggered grain boundary serration with intergranular carbides. In addition, the carbides in serrated samples are seen to grow in a preferred crystallographic orientation. This is demonstrated by means of diffraction patterns obtained by EBSD. Figure 11 demonstrates that carbide growth direction is aligned with the $\left\{\begin{array}{lll}1 & 1 & 1\end{array}\right\}$ slip planes.

Investigation of the carbide distribution in the serrated case was carried out under all test conditions. SEM image intensities were used to segment carbide particles and their centers of mass were recorded relative 

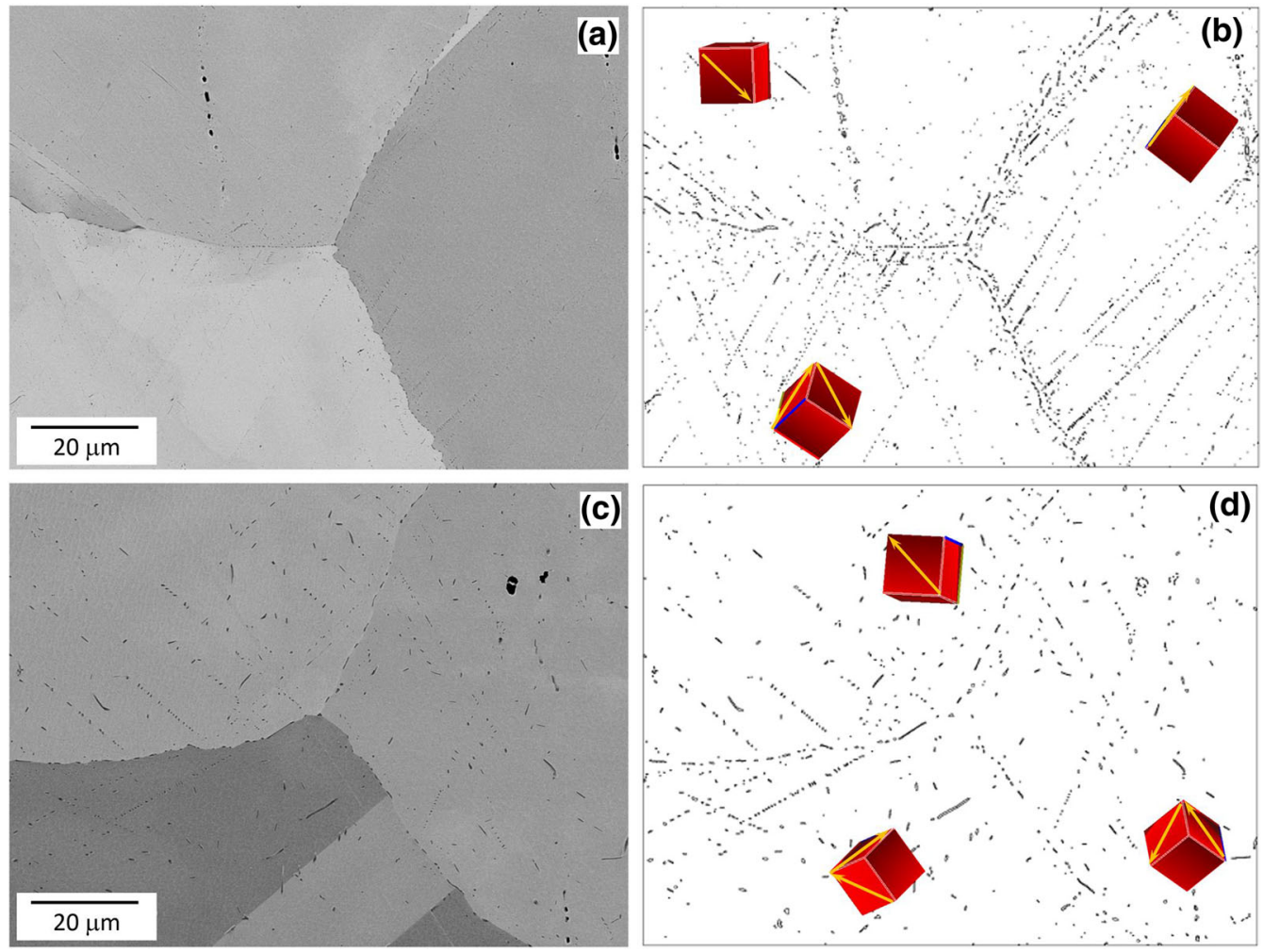

Fig. 11 - Serrated grain boundary sample interrupted by 5 pct creep strain at $(a) 815^{\circ} \mathrm{C} / 70 \mathrm{MPa}$ and $(c) 900{ }^{\circ} \mathrm{C} / 40 \mathrm{MPa}$. Carbides are outlined in $(b)$ and $(d)$ where it demonstrated preferred growth orientations. Unit cell orientations were extracted from EBSD data and stitched next to each grain. $\left\{\begin{array}{lll}1 & 1 & 0\end{array}\right\}$ directions on $\left\langle\begin{array}{llll}1 & 1 & 1\end{array}\right\rangle$ planes are labeled with yellow arrows. These directions are parallel to the carbides. It suggests carbide growth is facilitated by mass transport on slip systems (Color figure online).

to the positions of the grain boundary. The number densities of carbides as a function of distance from the ground boundary were averaged over three representative boundaries and are shown in Figure 17. No carbides were observed at $700{ }^{\circ} \mathrm{C}$, but carbides were frequently observed at higher test temperatures. The width of the carbide region is more extended at greater temperature, around $35 \mu \mathrm{m}$ at $815^{\circ} \mathrm{C}$ and $85 \mu \mathrm{m}$ at $900{ }^{\circ} \mathrm{C}$. With the increasing temperature, the carbides also become lowered in frequency; this suggests the carbides formed in the vicinity of grain boundary regions are originally from intergranular carbides.

Furthermore, magnified images of initial creep curves are shown in Figure 5. It is interesting to note that nonserrated samples possess lower minimum creep rates in the beginning, despite their lower final creep life. From the investigation on carbide distribution under interrupted conditions, this is believed to be contributed by in situ precipitation of smaller and higher densities of intragranular type carbides that provided precipitation strengthening. On the contrary, much of carbon in serrated samples was consumed via precipitation of grain boundary carbides, and less intragranular carbides were able to form. It is also interesting to note the coexistence of grain boundary precipitates and serration is always the case for the present study, which agrees well with other findings in the literature. The phenomenon of serration is de facto always associated with some types of grain boundary precipitates. Therefore, to explicitly evaluate the effects of grain boundary serration and precipitates that formed in correspondence is not feasible. Admittedly, the coexistence of precipitate/ serration may not always be beneficial, as the final properties might be sacrificed by way of losing some intragranular strength.

The carbide formation near grain boundaries might be facilitated by two possible mechanisms. One is due to faster diffusion path (pipe diffusion) where the nucleation sites are provided by dislocations. Another possible mechanism may be mass transport by dislocation climb, analogous to $\gamma^{\prime}$ phase rafting, ${ }^{[40]}$ when a gliding dislocation being trapped by an intergranular carbide in the first grain, it climbs at matrix/carbide interfaces and eventually escapes. The latter is believed to be dominating during the process, because with decreasing stress, slip bands are less pronounced from 170 to $40 \mathrm{MPa}$, as for the number of nucleation sites. In contrast, slip transfer becomes easier, as evidenced by the GND density maps. Therefore, at higher temperatures, slip transfer is thought to require less effort despite the pinning carbides.

\section{B. Dislocation Accumulation}

Creep testing was shown to induce dislocation cell structures in all cases. Average cell sizes were smaller for the higher-stress/lower-temperature tests, and were consistently slightly smaller for the serrated microstructure. 


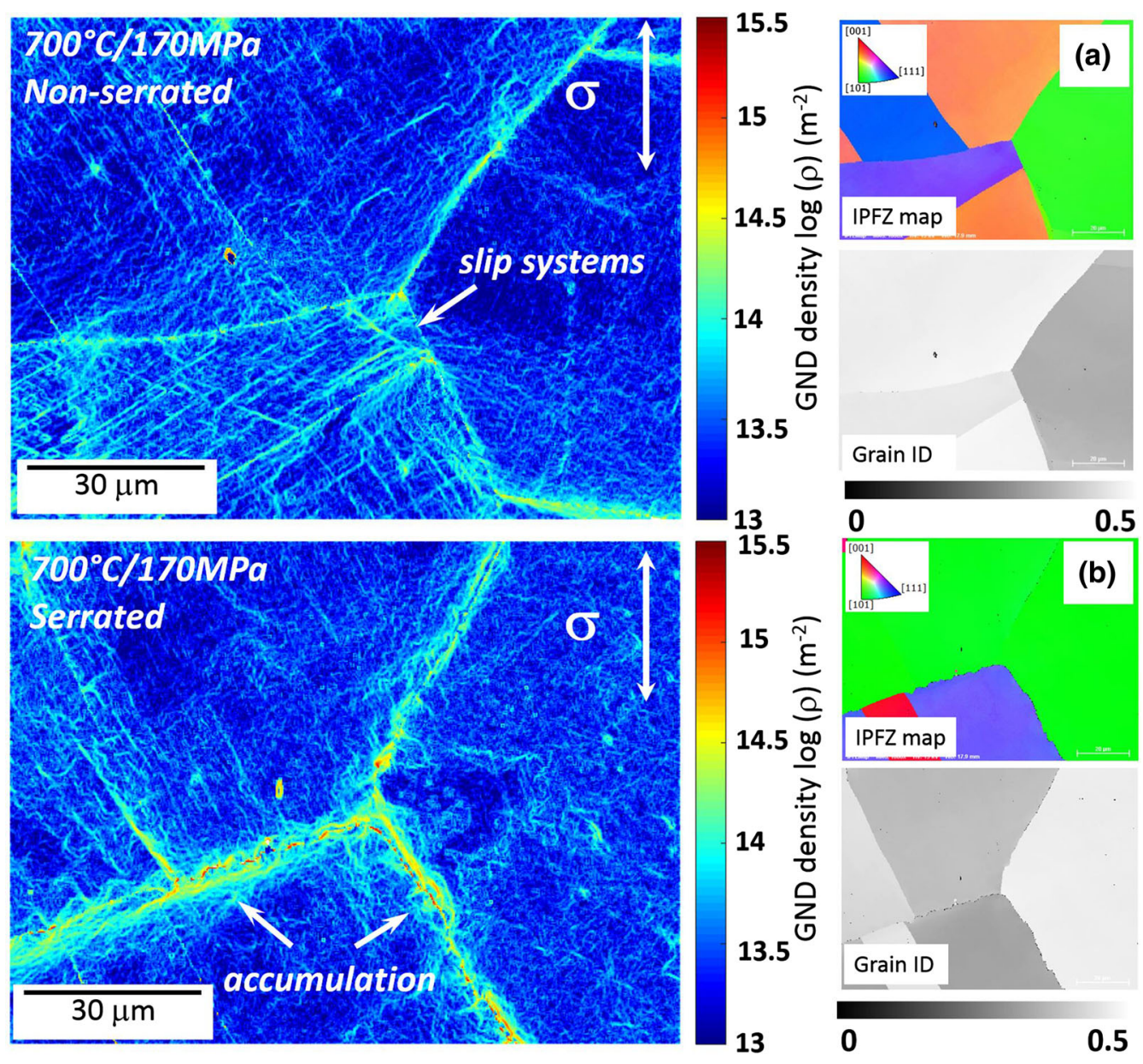

Fig. 12-GND density maps of interrupted specimens of $(a)$ nonserrated and $(b)$ serrated specimens at $700{ }^{\circ} \mathrm{C} / 170 \mathrm{MPa}$, together with inverse pole figure and schmid factor map, which shows the locations of the grains. GND density values are accumulated near grain boundary in serrated sample, whereas slip transfer seems to be fairly easy for nonserrated specimen (Color figure online).

For the tests interrupted at 5 pct strain, the dislocation cell structures had not yet formed fully, but there are signs of this beginning preferentially in regions close to grain boundaries and triple junctions.

At $700{ }^{\circ} \mathrm{C}$, the GND density is more localized around grain boundary regions with the serrated architecture, which suggests a role of carbides in preventing slip transfer. At $815{ }^{\circ} \mathrm{C}$, for nonserrated samples, the intersections, between three grain boundaries or between twin-grain boundaries, were shown to be associated with high GND density. In contrast, the serrated samples showed no particular dislocation accumulation in such grain intersections; instead, they show entanglement of GND with coarse carbides near the whole grain boundary region. At $900{ }^{\circ} \mathrm{C}$, such intersections were more pronounced where twin boundary and grain boundary intersect. However, no GND accumulations were found at twin-grain boundary intersections in serrated grain boundary samples under any conditions.

Schmid factor maps displayed next to each GND density map further supports the observation. In Figures 12, 13, and 14, lighter grains are the ones possessing higher magnitude of schmid factors, and hence are more prone to slip. In the case of nonserrated grain boundaries at $815^{\circ} \mathrm{C}$, the high GND density was localized at regions where notable schmid factor differences were found, i.e., the triple junction region in this case. This is understandbly due to the incompatibility of plasticity of different grains. However, despite the differences in the serrated case, GND density localization seems mostly independent of schmid values. It is again more pronounced under $900{ }^{\circ} \mathrm{C}$ conditions, where the twin-grain boundary intersection regions in the nonserrated case share a similar value of schmid factor, although this shows a severe GND density concentration. In contrast, the twin-grain boundary intersection shows more difference in schmid values, but was found to have a negligible accumulation of GND densities.

The high GND density intersections of this kind in nonserrated microstructures are believed to act as dislocation sources during creep, and possibly cavitation-initiation sites. Therefore, further SEM study was conducted near twin-grain boundary intersections in both microstructures. As confirmed by a number of different locations, triple junctions and twin-grain boundary intersections were found to be prone to 

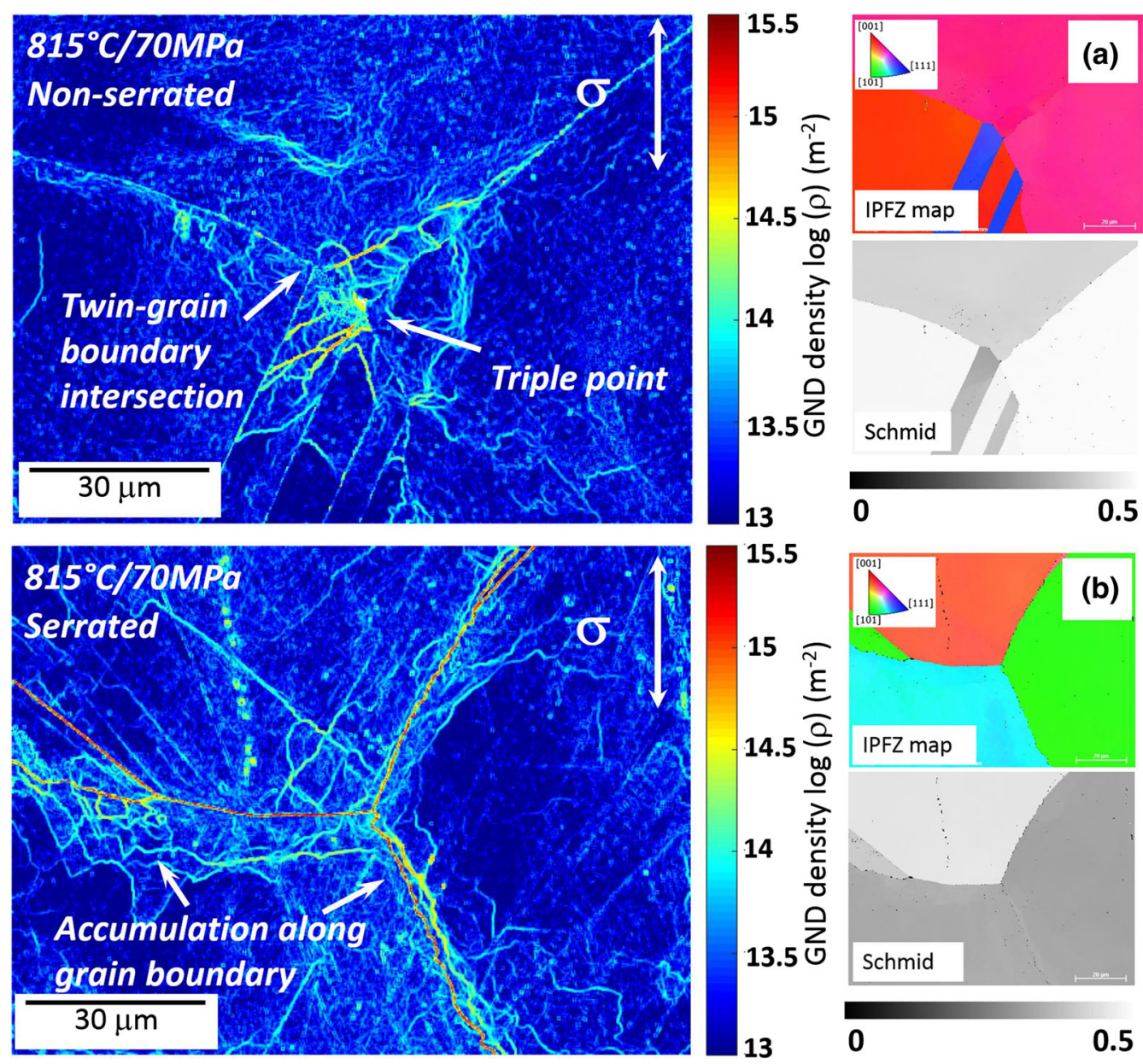

Fig. 13- GND density maps of interrupted specimens of $(a)$ nonserrated and $(b)$ serrated specimens at $815^{\circ} \mathrm{C} / 70 \mathrm{MPa}$, together with inverse pole figure and schmid factor map. Dislocation cell structures has initiated. GND density were highest at triple junction and twin-grain boundary intersection in nonserrated specimen, in contrast, GND density were highest near entire grain boundary region where carbides located (Color figure online).

cavitation in the nonserrated case. As shown in Figure 18, small cracks were frequently found to be associated with those intersections - either twin-grain boundary intersections or triple junctions. However, no such cracks/voids were observed in any interrupted tests on serrated grain boundary architectures, in agreement with the HR-EBSD results. Hence, nonserrated grain boundaries are more prone to initiate cavities, particularly near intersections between twin and grain boundaries, where high stress concentrations are likely to build up.

Previous study by Carter et al. also found the same tendency of such intersections using a Digital Image Correlation (DIC) approach. ${ }^{[41]}$ The reason why serrated grain boundaries do not suffer from strain accumulation probably relates to the presence of coarse carbides near and on grain boundaries. See, for example, Figure 14, where dislocation loops were identified where the carbides are located. This suggests the Orowan-looping and related mechanisms are operative where coarser carbides are more easily bowed around and circumvented. In reflection of this phenomenon, the EBSD image of fractured cross sections further supports the observation. Figures 7 and 8 both display a large number of internal cracks, which mostly correspond to grain boundaries adjacent to triple junctions or twin/ grain boundary intersections.

\section{Assessment of Degree of Cavitation}

In terms of total cavitation volume, for nonserrated grain boundary specimens, the extent measured is always remarkably higher-almost twice that in the serrated ones-more damage due to cavitation is expected. Furthermore, an interesting point is that serrated specimens are more frequently shown in $815^{\circ} \mathrm{C}$ to $900{ }^{\circ} \mathrm{C}$ conditions -1690 and 6154 counts (serrated) compared to 1053 and 3813 counts (nonserrated) - which is primarily contributed by the small size cavities. This is believed mostly contributed by increased actual grain boundary length due to the nature of serration that provided more cavity nucleation sites. In summary, serrated specimens have more but smaller cavities, whereas nonserrated ones have fewer but larger ones. Moreover, the size and frequency in both microstructures reflects a relation of direct proportionality over significant variations in temperatures and stresses, see Figure 19. The cavitation volume is plotted 

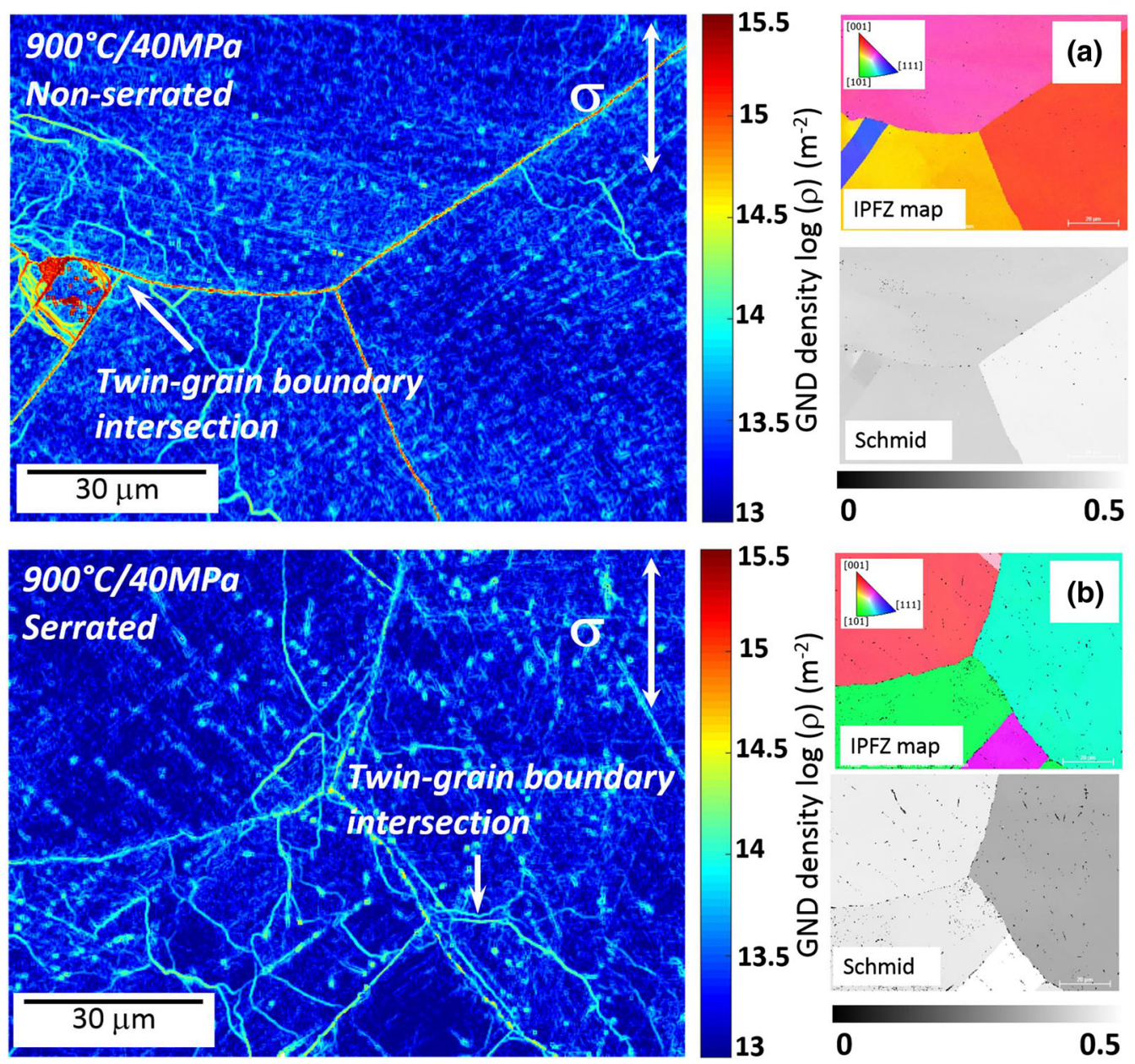

Fig. 14-GND density maps of interrupted specimens of $(a)$ nonserrated and $(b)$ serrated specimens at $900{ }^{\circ} \mathrm{C} / 40 \mathrm{MPa}$, together with inverse pole figure and schmid factor map. Dislocation cell structures started to grow. GND density were again accumulated at twin-grain boundary intersection for nonserrated specimen. Serrated specimen shows only higher GND density near carbides (Color figure online).

against frequency, so the slope represents average cavity volume is consistent in all conditions, $1.6 \times 10^{-3}$ and $6.5 \times 10^{-4} \mathrm{~mm}^{3}$ for nonserrated and serrated, respectively. It is then deduced that the average size of cavitation is independent of the creep conditions, but a function of grain boundary morphologies. A further point to be made here is that the growth behavior is significantly depressed due to serration. Rupture life and ductility improvements are gained by inhibiting cavity link-ups. The current study is the first quantitative cavitation analysis completed in $3 \mathrm{D}$ on understanding the serration effect, which has allowed greater insight into cavitation growth resistance.

The cell structures developed at $815{ }^{\circ} \mathrm{C}$ and $900{ }^{\circ} \mathrm{C}$ further support the argument above on cavitation volume and corresponding damage that it represents. The cell sizes are known to be inversely related to the stress that specimen experiences; therefore, an increase in cell size reflects lower stress applied, which is consistent in both microstructures. Now, while we consider the cases in serrated and nonserrated morphologies, we observe that under the same condition, the serrated microstructure always has a larger cell size than that of the nonserrated cases. The difference in true stresses is considered here. The X-ray computed tomography makes it clear that all the samples exhibit considerable porosity. This means that the more the cavitation damage a material is experiencing, the higher the true stress that is experienced due to a reduction in the load-carrying cross section. Since the cavitation volume is overwhelmingly higher in the nonserrated microstructure, the true stresses are indeed larger compared with the serrated case.

A comprehensive study on fracture and deformation mechanisms has been completed by Frost \& Ashby on nichrome $\left(\mathrm{Ni}-18 \mathrm{Cr}\right.$ wt pct), ${ }^{[4,43]}$ a very similar alloy, which can be used to rationalize the fracture mode in the present material. The fracture mode determined under $700{ }^{\circ} \mathrm{C} / 170 \mathrm{MPa}$ condition is a mixture of transgranular and intergranular types, consistent with the power law regime. Under the $815^{\circ} \mathrm{C}$ to $900{ }^{\circ} \mathrm{C}$ conditions, the deformation is still power-law controlled, but fracture mode is largely intergranular. This is in agreement with current observations made by fractography. However, the serrated microstructure always exhibits more transgranular features than the nonserrated case at lower test temperatures, particularly at $815^{\circ} \mathrm{C}$. The observation suggests a higher 


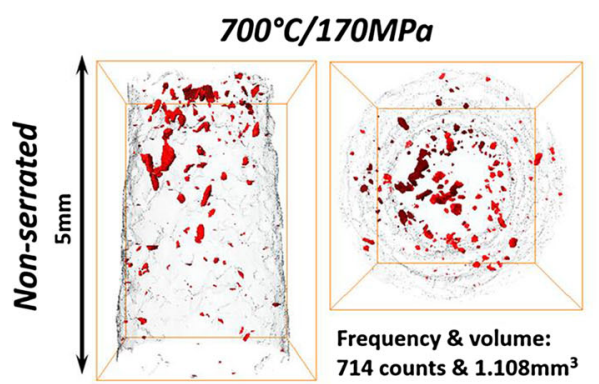

(a)

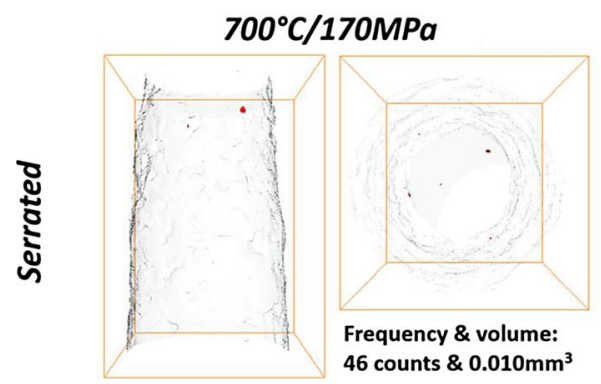

(d) $815^{\circ} \mathrm{C} / 70 \mathrm{MPa}$

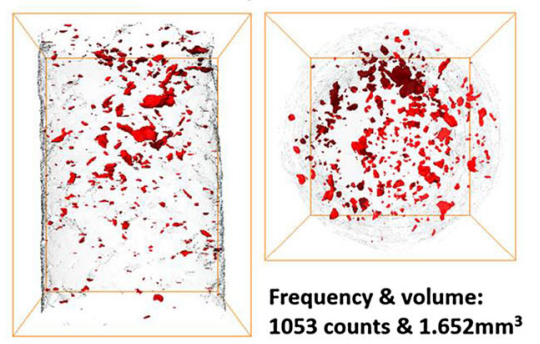

(b)

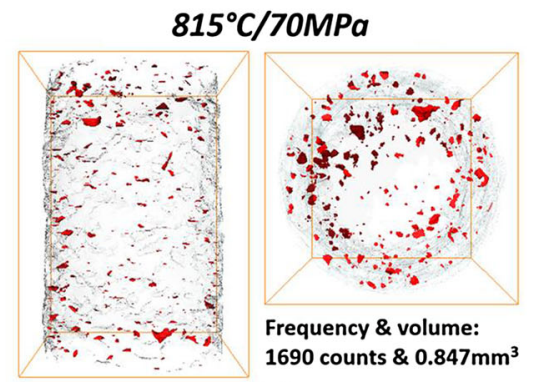

(e) $900^{\circ} \mathrm{C} / 40 \mathrm{MPa}$

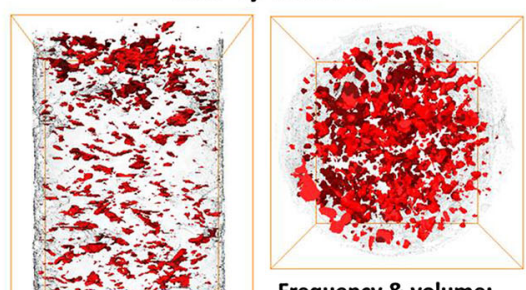

Frequency $\&$ volume: 3813 counts $\& 6.103 \mathrm{~mm}^{3}$

(c)

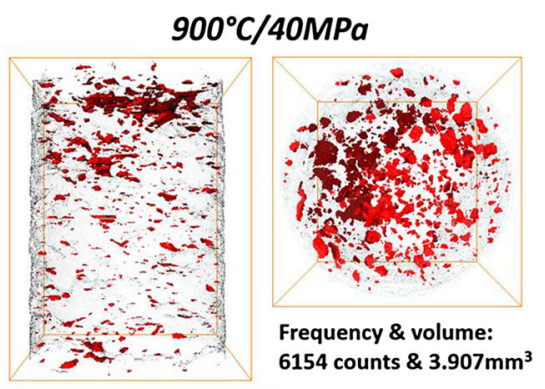

(f)

Fig. 15-3D reconstruction of fractured creep specimens from side and top views showing cavitation distribution, where red represents cavities. Two metrics were used for damage assessment, cavitation counts (frequency) and volume, which are labeled next to each specimen. The former takes account of small size cavitation, the latter takes account of ultimate damage. ( $a$ through $c$ ) displayed nonserrated samples and $(d$ through $f)$ for serrated ones. In higher temperature and lower stress regime, cavitation content is increased. Serration has strong resistance in cavitation propagation, as demonstrated with reduced cavitation volume by inhibiting coalescence of small cracks (Color figure online).

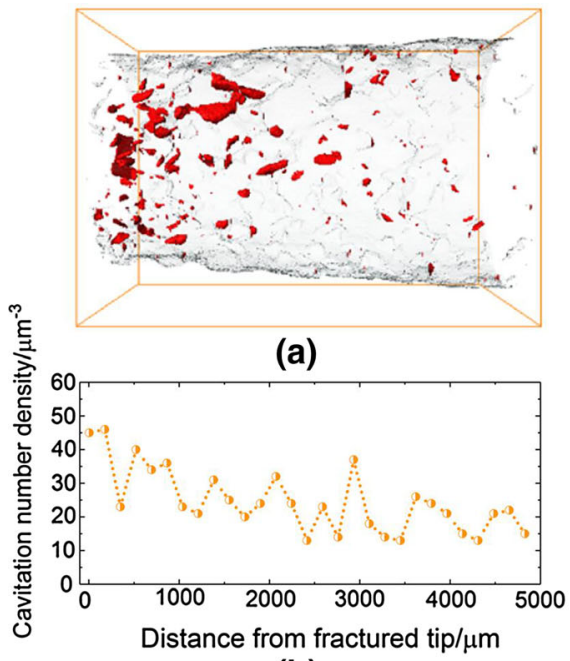

(b)

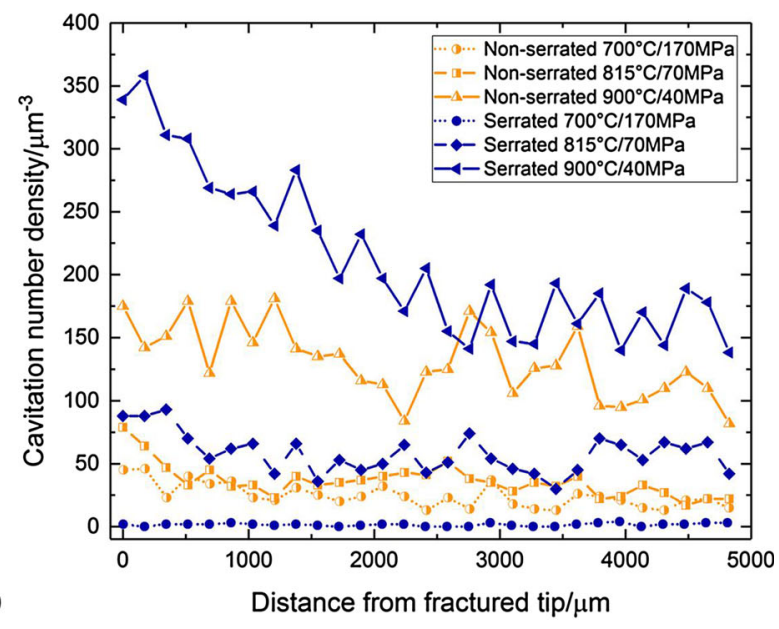

(c)

Fig. 16 - Cavitation number density vs distance from fracture tip. (a) and (b) represents a specific example of such a fracture tip and its cavitation profile over distance. $(c)$ Represents cavitation profile over distance for both microstructures at all creep conditions (Color figure online).

transition temperature is caused by serration due to cavitation resistance. It is well understood in the literature - and also verified in the current creep tests - that the cavitation limits ductility significantly. Although some intergranular features are determined to be active during creep, impact of cavitation is limited at $700{ }^{\circ} \mathrm{C}$, (the most affective damaging mechanisms being contributed by plasticity), obviously due to the significant creep strain. Twelve-slip systems could be active regardless of grain boundary morphology, and hence, no marked change in creep life was observed. Consequently, with the increasing temperature and decreasing stress, a transition to intergranular fracture emerged in the present experiment, where cavitation plays a more influential role.

To summarize, in the current study, grain boundary serration has been proven to enhance intergranular cracking resistance, both by stagnation of cavitation 

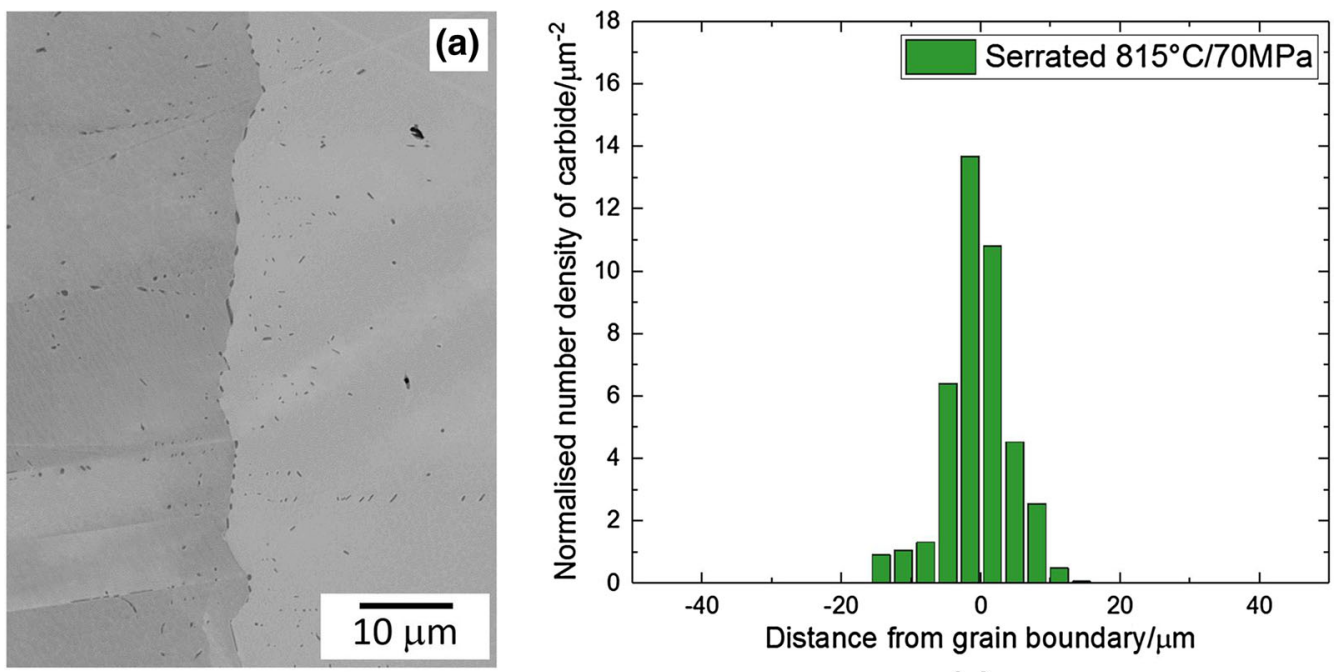

(c)

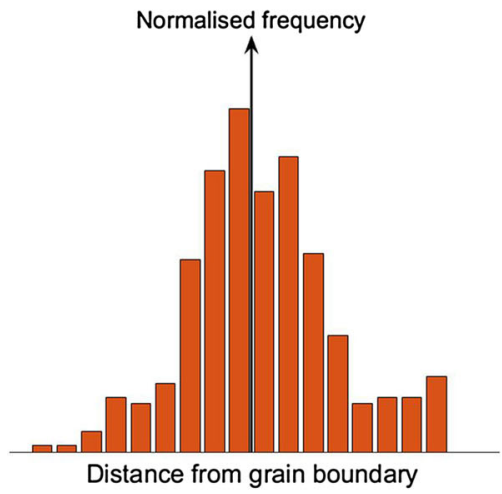

(b)

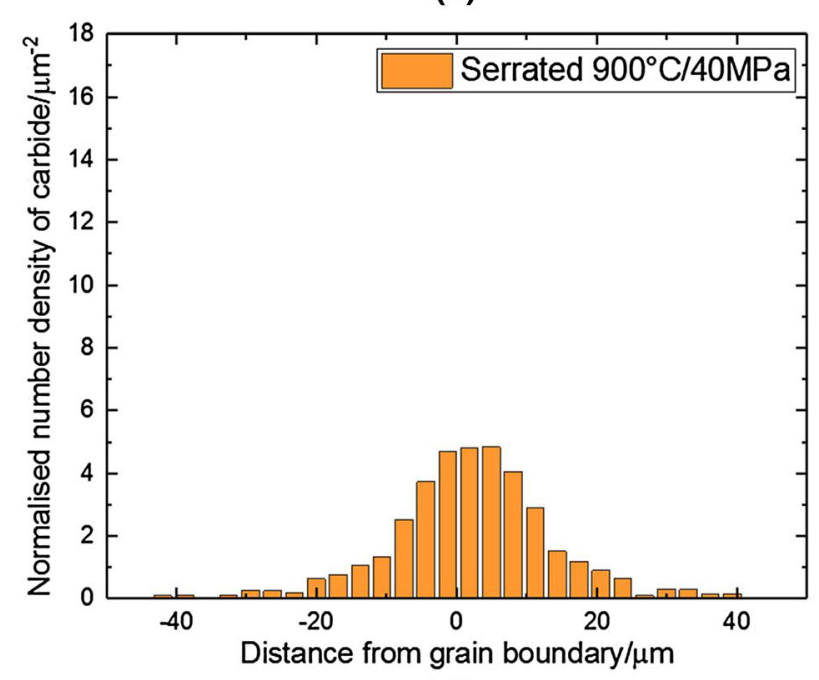

(d)

Fig. 17-Carbide distribution in relation to distance from grain boundary in the serrated case. $(a)$ and $(b)$ represent a specific example of a grain boundary used for analysis taken from interrupted specimen tested under $900{ }^{\circ} \mathrm{C} / 40 \mathrm{MPa}$ condition. Its number density frequency $v s$ distance is represented in (b). Accumulated carbide distribution measured for several grain boundaries for $815^{\circ} \mathrm{C}$ and $900{ }^{\circ} \mathrm{C}$ are exhibited in $(c)$ and $(d)$, respectively (Color figure online).

nucleation and its subsequent growth. Serration has conferred no beneficial effect on transgranular deformation, but it is not detrimental either.

\section{SUMMARY AND CONCLUSIONS}

The following specific conclusions can be drawn from this study.

1. In alloy Inconel 600, the degree of grain boundary serration is shown to be sensitive to the details of heat treatment and in particular, to the rate of cooling beyond the carbide solvus temperature; by varying this, significant differences in the degree of serration occur. Hence, it demonstrated that it is possible to develop microstructures of different degrees of serration, but also of other microstructures with identical grain size and twin boundary fraction.

2. The creep responses of serrated and nonserrated microstructures were assessed. A transition in deformation mode from mainly transgranular at $700{ }^{\circ} \mathrm{C} / 170 \mathrm{MPa}$ to intergranular-dominant cracking at $900{ }^{\circ} \mathrm{C} / 40 \mathrm{MPa}$ was observed, when the creep ductility was much reduced in comparison. Rupture lives were enhanced by serrated grain boundaries in the high-temperature/low-stress regimes.

3. Under the $815^{\circ} \mathrm{C} / 70 \mathrm{MPa}$ and $900{ }^{\circ} \mathrm{C} / 40 \mathrm{MPa}$ conditions, serrations improved the creep life by about 40 pct; however, no marked improvement was observed under $700{ }^{\circ} \mathrm{C} / 170 \mathrm{MPa}$. Thus, serrated grain boundaries conferred no beneficial effects when transgranular-type deformation is dominating, but were more effective for intergranular-type fractures. 

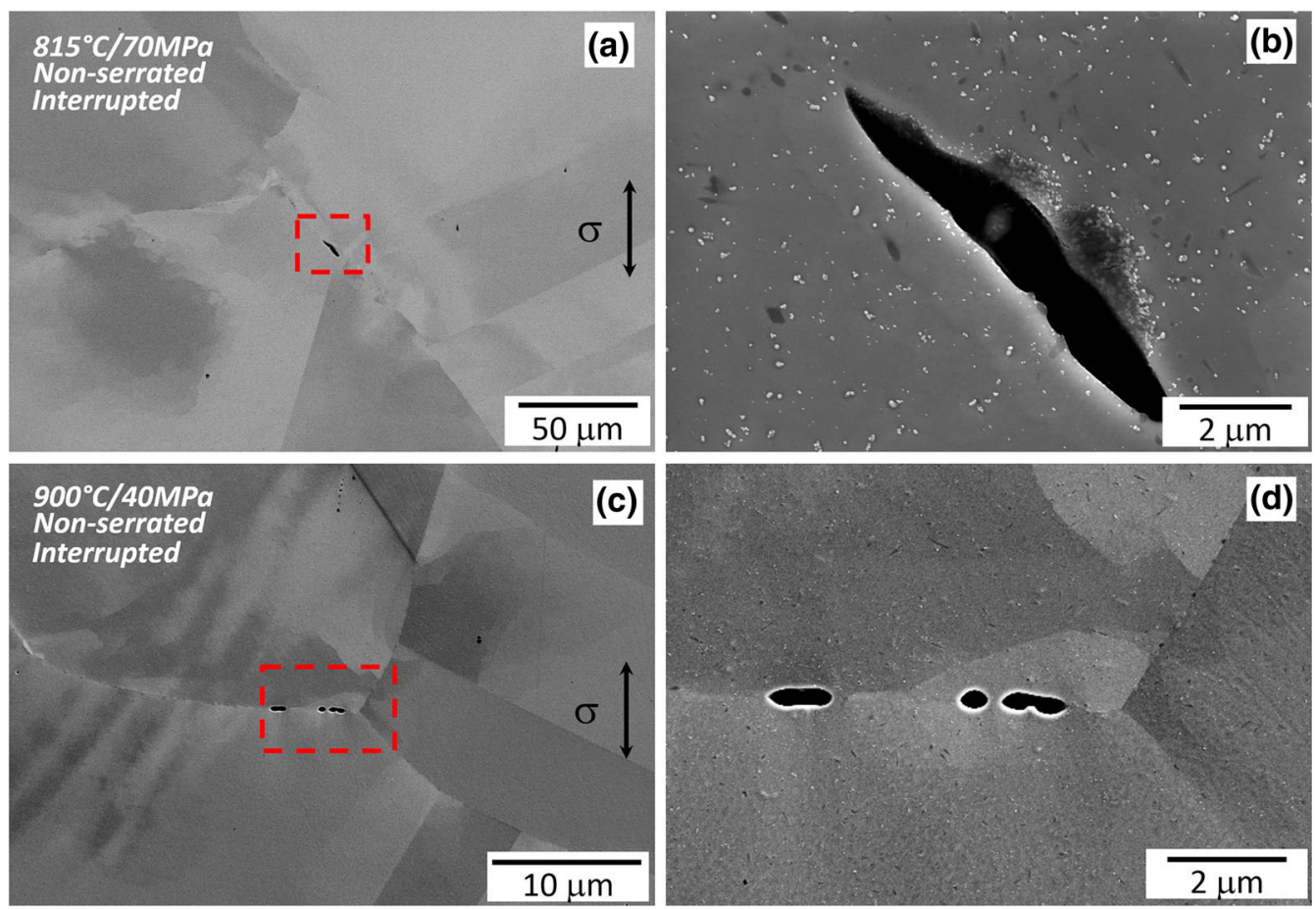

Fig. 18- Typical cavities observed in nonserrated material during interrupted creep test under $(a)$ and $(b) 815{ }^{\circ} \mathrm{C} / 70 \mathrm{MPa}$ and $(c)$ and $(d) 900{ }^{\circ} \mathrm{C} /$ $40 \mathrm{MPa}$ conditions, at different magnifications. It shows that triple junction and twin-grain boundary intersections are the nucleation points of cavities.

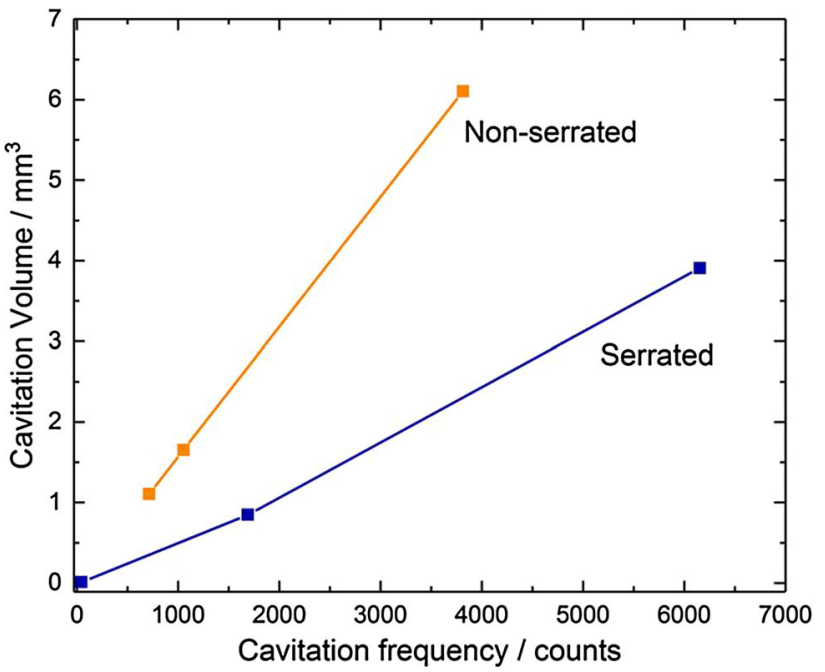

Fig. 19- Cavitation volume against frequency curve for both grain boundary morphology materials. The cavity volume and frequency are directly proportional, and the slope represents the average cavitation volume within each microstructure. The cavity volume is independent of creep conditions but a function of microstructures.

4. Under the $815^{\circ} \mathrm{C} / 70 \mathrm{MPa}$ and $900{ }^{\circ} \mathrm{C} / 40 \mathrm{MPa}$ conditions, twin-grain boundary intersections have been shown - consistent with their high GND densities - to be the initiation points for dislocation sources and cavitation. Serrated grain boundaries do not suffer so greatly from this effect and appear to present greater resistance to cavity formation.
5. Cavitation damage becomes more severe with the increasing temperature. Under the higher-temperature conditions employed, serrated samples produce a large number of small cavities, but with small cavitation volumes overall; nonserrated samples produce larger cavities and bigger cavitation volumes in total. Thus, the growth of cavities is greatly suppressed by serration.

6. Cavitation size in Inconel 600 is sensitive to microstructure; its volume and frequency are directly proportional regardless of the creep conditions, for both nonserrated and serrated grain boundary materials. However, average cavitation volume that can be obtained-determined by the slope of this relation - is related to grain boundary morphology.

7. Subgrain boundary cell dislocation structures were characterized and measured using cross-correlation-method-based HR-EBSD. The cells were larger for serrated rather than nonserrated samples under the same creep condition. Cavitation had an impact on cell sizes by increasing porosity, which eventually increased the true stress thus accelerating the creep rate.

8. The current study has confirmed life enhancement in time-dependent intergranular deformation on the account of grain boundary serration. The knowledge generated is believed to be transferable to a wide class of engineering alloys that are being used nowadays; with simple alteration in heat treatment, the properties of an alloy can be re-engineered. 


\section{ACKNOWLEDGMENTS}

The use of facilities funded by EPSRC Grants EP/ M02833X/1 and EP/J013501/1 is gratefully acknowledged. Roger Reed acknowledges financial support from EPSRC Grant EP/M005607/01. We would like to show our gratitude to Junliang Liu and Dr Andrew Lui for their assistance with Avizo software and X-ray computed tomography setup.

\section{OPEN ACCESS}

This article is distributed under the terms of the Creative Commons Attribution 4.0 International License (http://creativecommons.org/licenses/by/4.0/), which permits unrestricted use, distribution, and reproduction in any medium, provided you give appropriate credit to the original author(s) and the source, provide a link to the Creative Commons license, and indicate if changes were made.

\section{REFERENCES}

1. J.M. Larson: Metall. Mater. Trans. A, 1976, vol. 7A, pp. 1497-1502.

2. O Miyagawa, M Yamanoto, and M Kobayashi: Superalloys, 1976, pp. 245-54.

3. A.K. Koul and G.H. Gessinger: Acta Metall., 1983, vol. 31 (7), pp. 1061-69.

4. P.R. Bhowal, E.F. Wright, and E.L. Raymond: Metall. Mater. Trans. A, 1990, vol. 21A, pp. 1709-17.

5. M.F. Henry, Y.S. Yoo, D.Y. Yoon, and J. Choi: Metall. Mater. Trans. A, 1993, vol. 24A, pp. 1733-43.

6. H. Loyer Danflou, M. Macia, T.H. Sanders, and T. Khan: Superalloys 1996, pp. 119-27.

7. H.U. Hong, I.S. Kim, B.G. Choi, M.Y. Kim, and C.Y. Jo: Mater. Sci. Eng. A, 2009, vol. 517 (12), pp. 125-31.

8. A.R.P. Singh, S. Nag, J.Y. Hwang, G.B. Viswanathan, J. Tiley, R. Srinivasan, H.L. Fraser, and R. Banerjee: Mater. Charact., 2011, vol. 62 (9), pp. 878-86.

9. L. Jiang, H. Rui, H. Kou, J. Li, G. Bai, and F. Hengzhi: Mater. Sci. Eng. A, 2012, vol. 536, pp. 37-44.

10. Y.S. Lim, D.J. Kim, S.S. Hwang, and H.P. Kim: Mater. Charact., 2014, vol. 96, pp. 28-39.

11. M. Terner, H.U. Hong, J.H. Lee, and B.G. Choi: Int. J. Mater. Res., 2016, vol. 107, pp. 229-38.

12. A.K. Koul and R. Thamburaj: Metall. Mater. Trans. A, 1985, vol. 16A, pp. 17-26.

13. R.J. Mitchell, H.Y. Li, and Z.W. Huang: J. Mater. Process. Technol., 2009, vol. 209 (2), pp. 1011-17.

14. X.D. Lu, Q. Deng, J.H. Du, J.L. Qu, J.Y. Zhuang, and Z.Y. Zhong: J. Alloys Compd., 2009, vol. 477 (1), pp. 100-03.

15. X.X. Yao, Y. Fang, H.T. Kim, and J. Choi: Mater. Charact., 1997, vol. 38 (2), pp. 97-102.
16. J.G. Yoon, H.W. Jeong, Y.S. Yoo, and H.U. Hong: Mater. Charact., 2015, vol. 101, pp. 49-57.

17. J. Choi, J. Lee, J. Lee, H. Hong, and D. Kim: Korean J. Met. Mater., 2015, vol. 53, pp. 1-12.

18. J. Beddoes and W. Wallace: Metallography, 1980, vol. 13, pp. 185-94.

19. G. Van Drunen, J. Liurdi, J. Lib. Wallace, and T. Terada: Conference on Advanced Fabrication Processes.

20. H. Loyer Danflou, M. Marty, and A. Walder: Superalloys, 1992, pp. 63-72.

21. D. Rice, P. Kantzos, B. Hann, J. Neumann, and R. Helmink: Superalloys 2008, pp. $139-147$.

22. A. Wisniewski and J. Beddoes: Mater. Sci. Eng. A, 2009, vol. 510, 511, pp. 266-72.

23. H.Y. Li, J.F. Sun, M.C. Hardy, H.E. Evans, S.J. Williams, T.J.A. Doel, and P. Bowen: Acta Mater., 2015, vol. 90, pp. 35569.

24. P. Kontis, H.A. Mohd Yusof, S. Pedrazzini, M. Danaie, K.L. Moore, P.A.J. Bagot, M.P. Moody, C.R.M Grovenor, and R.C. Reed: Acta Mater., 2016, vol. 103, pp. 688-99.

25. P. Kontis, E. Alabort, D. Barba, D.M. Collins, A.J. Wilkinson, and R.C. Reed: Acta Mater., 2017, vol. 124, pp. 489-500.

26. E. Alabort, D. Barba, S. Sulzer, M. Liner, N. Petrinic, and R.C. Reed: Acta Mater., 2018.

27. A.C. Yeh, K.W. Lu, C.M. Kuo, H.Y. Bor, and C.N. Wei: Mater. Sci. Eng. A, 2011, vol. 530, pp. 525-29.

28. J.W. Lee, D.J. Kim, and H.U. Hong: Mater. Sci. Eng. A, 2015, vol. 625, pp. 164-68.

29. Y.Q. Chen, E. Francis, J. Robson, M. Preuss, and S.J. Haigh: Acta Mater., 2015, vol. 85, pp. 199-206.

30. R.J. Mitchell, M.C. Hardy, M. Preuss, and S. Tin: Superalloys, 2004, pp. 361-70.

31. R.C. Reed: The Superalloys: Fundamentals and Applications, Cambridge University Press, Cambridge, 2006.

32. K.K. Mehta, R. Mitra, and S. Chawla: Mater. Sci. Eng. A, 2014, vol. 611 , pp. $280-89$.

33. J.R. Davis: ASM Specialty Handbook Heat-Resistant Material. ASM International, 1997.

34. A.J. Wilkinson, G. Meaden, and D.J. Dingley: Ultramicroscopy, 2006, vol. 106 (4), pp. 307-13.

35. A.J. Wilkinson and D. Randman: Philos. Mag., 2010, vol. 90 (9), pp. 1159-77.

36. T.B. Britton and A.J. Wilkinson: Ultramicroscopy, 2012, vol. 114, pp. 82-95.

37. T.J.A. Slater, R.S. Bradley, G. Bertali, R. Geurts, S.M. Northover, M.G. Burke, S.J. Haigh, T.L. Burnett, and P.J. Withers: Sci. Rep., 2017.

38. P.S. Karamched and A.J. Wilkinson: Acta Mater., 2011, vol. 59 (1), pp. 263-72.

39. J. Jiang, T. Ben Britton, and A.J. Wilkinson: Int. J. Plast., 2015, vol. 69, pp. 102-17.

40. Z. Zhu, H. Basoalto, N. Warnken, and R.C. Reed: Acta Mater., 2012, vol. 60 (12), pp. 4888-4900.

41. J.L.W. Carter, M.W. Kuper, M.D. Uchic, and M.J. Mills: Mater. Sci. Eng. A, 2014, vol. 605, pp. 127-36.

42. M.F. Ashby, C. Gandhi, and D.M.R. Taplin: Acta Metall., 1979, vol. 27 (5), pp. 699-729.

43. H.J. Frost and M.F. Ashby: Deformation-Mechanism Maps, The Plasticity and Creep of Metals and Ceramics, Pregamon Press, New York, 1982. 